\title{
EMPRESA, DERECHOS HUMANOS Y SOCIEDAD DE LA INFORMACIÓN
}

\author{
ENTERPRISE, HUMAN RIGHTS AND INFORMATION SOCIETY \\ EMPRESA, DIREITOS HUMANOS E SOCIEDADE DA INFORMAÇÃO
}

\begin{abstract}
GREICE PATRICIA FULLER
https://orcid.org/0000-0002-9510-3437 / http://lattes.cnpq.br/7129039334107416/ greicepf@uol.com.br Pontifícia Universidade Católica de São Paulo, PUC/SP. Centro Universitário das Faculdades Metropolitanas Unidas, FMU.
\end{abstract} São Paulo, SP, Brasil.

JOSÉ LUIZ BÁTIZ LOPEZ https://orcid.org/0000-0003-4157-8290 / http://lattes.cnpq.br/8274221790835941 / josebatiz@yahoo.com Universidad de Navarra. Pamplona, Navarra, Espanha.

\begin{abstract}
RESUMO
O trabalho apresenta como finalidade proceder à análise da interrelação entre empresa, direitos humanos e sociedade da informação em face do desenvolvimento do século XXI. O desenvolvimento do trabalho subsume os direitos humanos aos objetivos das empresas sob a ótica do jusnaturalismo de John Locke, plasmando a relação indissociável entre empresa e democracia e o papel da sociedade da informação em face do mercado econômico que pode servir como instrumento de possível vulneração aos mesmos. Nesse sentido, verifica-se que desde o Direito Internacional consideram-se os acordos comerciais e institucionais como facilitadores às relações comerciais, bem como protetivos a direitos humanos. Conclui-se que os temas se relacionam com propostas para a melhoria das condições sociais preconizadas constitucionalmente e o desenvolvimento econômico de um país. 0 presente trabalho utiliza o emprego de metodologia consistente na técnica analítica, na qual são avaliados os aspectos de índole sistemáticoconstitucional das normas jurídicas, agregada ao enfoque dialético e multidisciplinar.
\end{abstract}

Palavras-chave: Empresa; direitos humanos; sociedade da informação; desenvolvimento econômico.

\begin{abstract}
This paper aims to analyze the interrelationship among enterprise, human rights and the information society in relation to the issue of development in the 21st century. The development subsumes the human rights and enterprises' objectives, according to natural law doctrine by John Locke, embodied in the inseparable relationship among enterprise, democracy, and the role of the information society in the face of the economic market as an instrument of possible violation of the human rights. In that sense, it is observed by international law that trade agreements and institutions that make possible commercial relations and protect human rights over business practices. It is concluded that the topics are related to the proposals for the improvement of the social conditions established in the Constitution and the economic development in a country. This analysis is carried out from the juridical-philosophical, dogmatic, doctrinal and casuistic approach and it uses the methodology consisting on the analytical technique, in which the systematic-constitutional aspects of legal norms are evolved, added to the dialectic and multidisciplinary vision.
\end{abstract}

Keywords: Enterprise; human rights; information society; development, economy. 


\section{RESUMEN}

Este trabajo presenta como finalidad analizar la interrelación entre empresa, derechos humanos y sociedad de la información frente al tema del desarrollo en el siglo XXI. El desarrollo del trabajo subsume a los derechos humanos y a los objetivos de las empresas según la doctrina iusnaturalista de John Locke, plasmando la relación indisociable entre empresa y democracia, y el papel de la sociedad de la información ante el mercado económico que puede servir como instrumento de posible vulneración de los derechos humanos. En ese sentido, se observa que desde el derecho internacional se consideran los acuerdos comerciales e instituciones que facilitan las relaciones comerciales, y protegen los derechos humanos sobre prácticas empresariales. Se concluye que los temas se relacionan con las propuestas para la mejora de las condiciones sociales establecidas en la Constitución y del desarrollo económico de un país. Este análisis es realizado desde el enfoque jurídico-filosófico, dogmático, doctrinario y casuístico y utiliza la metodología consistente en la técnica analítica, en la cual son evolucionados los aspectos de orden sistemáticoconstitucional de las normas jurídicas, agregado a la visión dialéctica y multidisciplinar.

Palabras clave: empresa; derechos humanos; sociedad de la información; desarrollo económico.

\section{SUMÁRIO}

INTRODUCCION; 1 EMPRESA Y DERECHOS HUMANOS; 1.1 Planteamiento del tema; 1.2 Locke y el capitalismo humanista; 2 LOS DERECHOS HUMANOS, LA ACTIVIDAD EMPRESARIAL Y LA SOCIEDAD DE INFORMACIÓN: UNA RELACIÓN INDISOCIABLE EN EL SIGLO XXI; 2.1 Aspectos generales; 2.2 Derechos Humanos, Empresas y Democracia; 2.3. La Sociedad de la información frente a las Empresas y a los Derechos humanos; 2.3.1. ¿La Sociedad de la información: una realidad perversa ante a los Derechos Humanos?; 2.3.2. Las Empresas ante el acceso a Internet y la vulneración de los Derechos Humanos; 2.3.3. ¿Dignidad empresarial: utopía frente a la Sociedad de la información y a los Derechos Humanos? 3 DERECHO, ECONOMÍA Y DESARROLLO, EXPERIENCIA DE LA TEORÍA A LA PRÁCTICA; 3.1 EI movimiento del Derecho y Desarrollo: una relación inseparable;4 TRANSICIÓN DEL ESTADO Y DEL MERCADO A LAS INSTITUCIONES; 4.1 Experiencias del Derecho en el desarrollo; 5 DESARROLLO ECONÓMICO; 5.1. Cadenas globales de Producción; 6 ACUERDOS E INSTITUCIONES INTERNACIONALES; 6.1 La protección de los derechos humanos en las cadenas globales de producción; CONCLUSIONES; REFERENCIAS.

\section{INTRODUÇÃO}

En este trabajo se analiza la intersección entre los temas de empresa, derechos humanos y sociedad de la información, así como de áreas de estudio que complementan la teoría y la práctica que se desarrolla por la interacción entre el Estado, la Sociedad y la Economía, dentro del campo del estudio del Derecho y Desarrollo.

Para tal fin se hace un estudio jurídico-filosófico entre derechos humanos, capitalismo y la corriente iusnaturalista de John Locke, indicando que el mercado posee fuentes propias basadas en la ley natural de la Fraternidad que impone la concretización del principio de la dignidad de la persona humana.

Aún se analiza de manera reflexiva-crítica a la sociedad de la información como herramienta para la concretización de la democracia, de los derechos humanos y de la dignidad empresarial. 
Además de lo anterior, se toma de referencia la resolución aprobada por el Consejo de Derechos Humanos, de las Naciones Unidas número 17/4 del 16 junio 2011 identificada como “Promoción y protección de todos los derechos humanos, civiles, políticos, económicos, sociales y culturales, incluido el derecho al desarrollo", de manera clara exhorta a los titulares de los Estados y a las empresas (nacionales y transnacionales) el "deber y la responsabilidad" de proteger las "libertades fundamentales" a través de "recursos judiciales o extrajudiciales efectivos" para actuar en consecuencia contra los abusos del poder por parte de las instituciones privadas (sin exclusión de las públicas) que los vulneran.

Por lo tanto, dicho exhorto, produce una obligatoriedad hacia el sistema judicial de los estados, de manera provisoria y correctora contra la vulneración de los derechos humanos. Por tal motivo, se pone en evidencia la necesidad de fortalecer la legislación nacional, para fortalecer la práctica jurídica en temas puntuales.

Este análisis es realizado desde el enfoque jurídico-filosófico, doctrinario y casuístico para que se llegue a la conclusión sobre la interrelación entre empresa, derechos humanos y sociedad de la información, utilizando la metodología basada en la técnica analítico- dialéctica.

\section{EMPRESA Y DERECHOS HUMANOS}

\subsection{Planteamiento del tema}

Por el objetivo de esta sección y por los factores metodológicos, resulta impredecible realizar un breve análisis de la definición de los derechos humanos, sobre la expresión y su alcance.

Las Naciones Unidas promulgaron en 1948, la necesidad de realizar pactos escritos y expresos, como la Declaración Universal de los Derechos Humanos, a la que siguieron los Pactos Internacionales de Derechos Civiles y Políticos y Derechos Económicos, Sociales y Culturales de 1966.

Bobbio afirma que la definición de los derechos humanos no es una cuestión de fácil resolución, porque se trata de una expresión vaga, ya que generalmente los conceptos sobre el asunto son tautológicos: "Derechos de los hombres son los que son del hombre en cuanto es 
hombre. Ellos solo nos dicen algo respecto al estatuto deseado o propuesto para estos derechos y no sobre su contenido". ${ }^{1}$

Sin embargo, es importante para fines pedagógico-jurídicos que se construya un concepto de la expresión en cuestión. Según Perez Luño, los derechos humanos suelen venir comprendidos como un conjunto de "facultades e instituciones que, en cada momento histórico, concretan las exigencias de la dignidad, la libertad y la igualdad humana, que deben ser reconocidas positivamente por los ordenamientos jurídicos". ${ }^{2}$

Después de este análisis puntual sobre los derechos humanos, es menester subrayar que hoy se buscan las iniciativas para la construcción de un mercado global más estable, equitativo e incluyente que fomente sociedades y mercados sostenibles y que tengan sus bases en el respeto a los derechos humanos. Por eso se manifiesta que el buen gobierno corporativo es especialmente necesario para alcanzar los objetivos de la justicia social, sostenibilidad y respeto de los derechos humanos. ${ }^{3}$ Aunque es necesario proteger los derechos humanos a través de la regulación estatal (normas jurídicas vinculantes) para mitigar los problemas, sin embargo, este aspecto regulatorio resulta complejo ante el enfoque del control y ejecución de las normas, resultando inefectivo para atacar las raíces del problema. ${ }^{4}$

Por lo tanto, no existen mecanismos eficaces y realmente impeditivos para garantizar el cumplimiento de estándares de ética para la defensa de los derechos humanos y, además, muchos de ellos descansan en iniciativas informales llevadas a cabo por ONGs o sindicatos locales independientes. ${ }^{5}$

En este trabajo se requiere poner de relieve el decisivo papel que está llamado a jugar el sector empresarial en todo el proceso de cambio, hacia una economía respetuosa con los derechos humanos fomentada sobre las bases de la sociedad de la información.

\footnotetext{
${ }^{1}$ BOBBIO, Norberto. A Era dos Direitos. Rio de Janeiro: Campus, 1992, p.17.

2 PEREZ LUÑO, Antonio Enrique. Los Derechos Fundamentales. Madrid: Tecnos, 2004, p.42.

3 TABRA OCHOA, Edison Paul. Solidaridad y Gobierno Corporativo de la Empresa. Barcelona: Bosch, 2015, p. 231.

${ }^{4}$ MORROW, P. A Pocket guide to Corporate Governance. Bold Institute, 2015, p. 4. Disponible en: http://corporate-responsibility.org/wp-content/uploads/2015/pocket-guide-to-corporate-governance.pdf. Acceso en: 26 de feb. 2017.

${ }^{5}$ DE JONGE, Alice. Transnational Corporations and International Law: Accountability in the Global Business Environment. Cheltenham-Northampton: Edward Edgar, 2011, p. 54-56
} 


\subsection{Locke y el capitalismo humanista}

Si hablamos sobre el equilibrio que debe existir entre el desarrollo de las nuevas tecnologías, derechos humanos y economía es menester el estudio de John Locke y la idea sobre el capitalismo humanista en su obra titulada "Tratado sobre el segundo Gobierno Civil".

El estudio sobre el tema empieza entre las enseñanzas de Locke, y se nota que él ha ejercido gran influencia en la Declaración de la Independencia norte-americana (1776); en la Revolución Francesa (1789); Declaración de los Derechos del Hombre y del Ciudadano (1789); Declaración Universal de los Derechos del Hombre (1948); en la concepción germinal de la separación de los poderes, posteriormente sistematizada por Montesquieu; en las ideas del sistema representativo del gobierno; y del constitucionalismo.

El citado filósofo comprendió que la sociedad civil surgió de la idea de la afirmación de los valores inherentes a los derechos y garantías individuales como forma de contraponerse al contexto histórico-social del absolutismo. Por lo tanto, afirma que debe existir una sociedad política establecida por medio de un pacto de consentimiento (contrato social) entre los hombres y el Estado donde sean consagrados especialmente los derechos naturales de libertad y propiedad. $^{6}$

La estructura del capitalismo es concebida en las ideas de Locke, especialmente la de que los hombres se reunieron y dieron origen al Estado para que se pudiera defender los derechos naturales, entre ellos, los de propiedad (libertades externas) y los de creencia (libertades internas). Según Comparato se dice que:

[...] se la doctrina de los derechos individuales como prerrogativas unidas a la propia naturaleza humana, hizo de Locke uno de los fundadores de la moderna teoría de los derechos humanos, la defensa por él desarrollada de la moderna teoría de los derechos humanos, y del derecho de la propiedad privada, acaba por convertirlo como uno de los padres fundadores de la civilización burguesa y uno de los santos patronos del sistema capitalista $[\ldots]^{7}$

Al reconocer el derecho subjetivo de la propiedad y compatibilizando las fuerzas del mercado con el objetivo de la realización de los derechos humanos en todas sus dimensiones para la satisfacción del principio de la dignidad de la persona humana, el régimen se considera capitalista humanista.

\footnotetext{
${ }^{6}$ FULLER, Greice Patrícia. A contemporaneidade do pensamento de John Locke no contexto do século XXI. Revista de Direito Constitucional e Internacional. São Paulo: Revista dos Tribunais, 2004, p.142.

${ }^{7}$ COMPARATO, Fábio Konder. Ética. São Paulo: Companhia das Letras, 2006, p. 220.
} 
ISSN 1981-3694

(DOI): $10.5902 / 1981369433710$

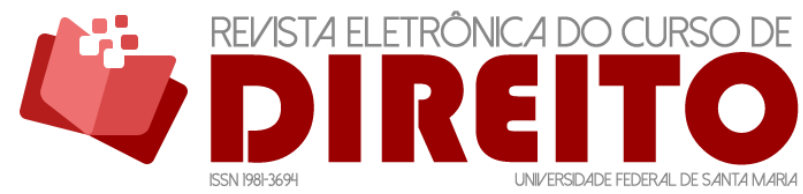

EMPRESA, DERECHOS HUMANOS Y SOCIEDAD DE LA INFORMACIÓN

La citada afirmación se encuentra en el Programa de las Naciones Unidas para el Desarrollo contemplada durante algunas décadas que las personas son la riqueza verdadera de las naciones y no solamente el crecimiento económico es suficiente para el progreso de un país: "equilibrar las evaluaciones del progreso puramente económico con indicadores 'socioeconómicos', que llevan en cuenta, criterios económicos, humanos y sociales y, como ocurre con muchos de ellos, criterios ambientales". ${ }^{8}$

Es menester complementar dichas ideas para que el sistema económico no se vuelva un sistema de opresión al individuo contra sus derechos preexistentes (naturales), Locke señaló que ante el derecho natural de la fraternidad los derechos individuales agregados deben ser horizontalmente garantizados contra los desequilibrios causados por ellos mismos en la comunidad. Así que la aplicación de los derechos humanos en la economía resuelve la cuestión respecto a la gestión económica global según la ley natural de la solidaridad, rechazando un modelo individualista y utilitarista de mercado.

Por lo tanto, un corolario de este pensamiento es la afirmación de que "si el Estado tiene que preocuparse de los más desvalidos, el presupuesto cada vez mayor de los gastos del Estado debe orientarse en las áreas sociales". 9 Es decir que el orden económico debe apoyarse en la sustentabilidad social, cultural, social y ambiental global, satisfaciendo el principio de la dignidad de la persona humana, exigiendo asegurar a todos, el mínimo para satisfacer la existencia digna, o sea, las externalidades que se refieren a la salud, alimentación, saneamiento ambiental, ocio, trabajo, vivienda, seguridad, asistencia social, asistencia a la niñez y a los desamparados.

Así que el capitalismo necesita ajustarse a la ley natural de la fraternidad para que propicie el ejercicio de los derechos de la libertad, igualdad y de la propiedad que fueron los tres derechos naturales defendidos en el Segundo Tratado sobre el Gobierno Civil. ${ }^{10}$ Es una idea que ya se encuentra traducida en la Constitución Brasileña de 1988 que es mencionada en el art. 170 que "El orden económico, fundado en la valorización del trabajo humano y en la libre iniciativa, tiene por fin asegurar la existencia digna a todos, según los preceptos de la justicia social (...)"11

\footnotetext{
${ }^{8}$ GADREY, Jean; JANY-CATRICE, Florence. Os novos indicadores de riqueza. São Paulo: Senac, 2006, p.17.

9 MARTINEZ, Gutemberg. Humanismo e economia: ética e responsabilidade. São Paulo: Bem Comum, n. 84, 2005, p. 41.

10 LOCKE, John. O Segundo Tratado sobre o Governo Civil. São Paulo: Edipro, 2014, p.42.

11 BRASIL, Constituição Federal (1988). Constituição da República Federativa do Brasil. Diário
} 
Además de la Constitución, la jurisprudencia decide según la ley natural de la fraternidad, conforme el precedente AgRg n. 152.229 0/01 de 28 de febrero de 2008 (Pleno del Tribunal de Justicia de São Paulo). Por voto unánime se reconoció la aplicación de la ley natural de la fraternidad ante el derecho a la salud que representa un derecho natural al mínimo existencial y ratifica el principio de la dignidad humana, siendo deber del Poder Judicial imponerlo al caso concreto. En el mismo sentido se puede observar la Apelación Civil n. 991.06.054960-3 de 30 de septiembre de 2010 dictada por la 11 a Cámara de Derecho Privado.

Es importante decir que cuando haya desequilibrio negativo en las externalidades y no se tenga él mismo resuelto, esta situación deberá ser solucionada subsidiariamente por el Estado, sociedad civil, incluyendo las personas físicas y en especial, las personas jurídicas de Derecho Privado, asegurando la vía del Poder Judicial siempre que sea impulsado por ellos. Así es porque la sociedad civil también es responsable en la concretización de los derechos humanos según el artículo $1^{\circ}$ de la Declaración Universal de los Derechos Humanos y por la interpretación sistemática de la propia Constitución Federal de 1988, especialmente en su Preámbulo.

Sin embargo, el fenómeno del capitalismo humanista depende del hombre y él vive en constante debate dialéctico entre la fraternidad y la búsqueda de sus propias satisfacciones, es decir que "desde el princípio, el hombre nacido en la tierra con su saludable instinto animal está en pelea con su alma y sus demonios." 12

\section{LOS DERECHOS HUMANOS, LA ACTIVIDAD EMPRESARIAL Y LA SOCIEDAD DE INFORMACIÓN: UNA RELACIÓN INDISOCIABLE EN EL SIGLO XXI}

\subsection{Aspectos generales}

Si estamos frente a una sociedad libre, democrática y plural siempre van a aparecer nuevas realidades, necesidades y cambios que despertarán nuevos derechos.

La incidencia de las nuevas tecnologías de información en el ámbito de las libertades ha caracterizado una nueva generación o redimensión de los derechos humanos, es decir, la aparición de los derechos humanos de la sociedad tecnológica.

Claro es que esta situación no implica la sustitución de los derechos ya existentes, porque el rol de las libertades no es algo cerrado y fijo en el tiempo, pero probablemente conlleva a la

Oficial da União. Brasília. DF. 5 out. 1988. Disponible en:

http://www.planalto.gov.br/ccivil_03/constituicao/constituicao.htm. Acceso em: 25 de ago. 2018.

12 JUNG, C. G. Os arquétipos e o inconsciente coletivo. Rio de Janeiro: Vozes, 2008, p. 38. 
ISSN 1981-3694

(DOI): $10.5902 / 1981369433710$

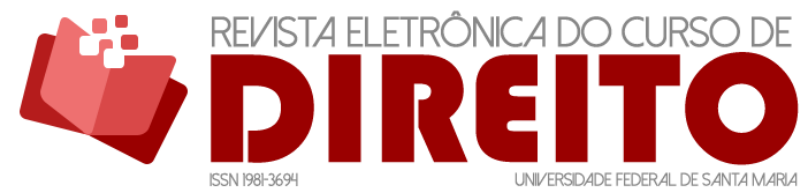

EMPRESA, DERECHOS HUMANOS Y SOCIEDAD DE LA INFORMACIÓN

aparición de nuevos derechos que surgen como imperativos de respuesta a una nueva realidad/necesidad histórica y que actuarán como preceptos axiológicos y pragmáticos.

Es indudable que la era tecnológica ha propiciado nuevas formas de ejercicio de derechos y una participación más activa de los ciudadanos y las empresas en la sociedad. Sin embargo, al lado de este aspecto positivo de la libertad informacional por las tecnologías, esta lo inherente a los deberes y posibilidades de vulneración en las esferas de otros derechos de la personalidad humana.

Así que la necesidad en la construcción de ideas y teorías sobre la responsabilidad informática frente a las empresas y colectividad es una realidad que reclama el estudio multidisciplinar no solamente de las ciencias jurídicas, sino de la filosofía, sociología, política y en especial, de la economía.

Por lo tanto, las empresas tendrán que acompañar la situación planteada por los derechos humanos y a su vez, por el tema de la responsabilidad informática y superar los retos que serán producidos entre la utilización de las tecnologías, la necesidad del desarrollo económico en una sociedad capitalista y el respeto a los derechos humanos de la personalidad en el ambiente de la sociedad de la información.

\subsection{Derechos Humanos, Empresas y Democracia}

Según Canotilho la democracia como concepción global de sociedad, entraña la transferencia del principio democrático (con las adaptaciones y limitaciones impuestas por condiciones de los sectores) para los varios 'subsistemas' sociales, o sea, sistemas de educación y cultura, comunicación social, administración pública, instituciones de previdencia (seguridad social, hospitales, residencias para personas mayores) y sectores económicos (empresas, v.g.). ${ }^{13}$ A este proceso, el autor nombra de democratización de la democracia, es decir, que el principio democrático necesita expandirse a los diferentes aspectos de la vida económica, social y cultural para que sea un principio fundamental del Estado y de la sociedad.

Más allá de estas ideas, la democracia puede ser sintetizada por la célebre frase citada por Abraham Lincoln como el "gobierno del pueblo, por el pueblo y para el pueblo", siendo que la participación es uno de sus elementos fundamentales y caracterizadores de la supremacía de la voluntad popular. Según Matteucci y Pasquino se puede afirmar que:

${ }^{13}$ CANOTILHO, J.J. Gomes. Direito Constitucional. Coimbra: Almedina, 1992, p. 421-432. 
El ideal democrático supone ciudadanos vigilantes a la evolución de la cosa pública, informados de los acontecimientos políticos, de los principales problemas, capaces de escoger entre las diversas alternativas presentadas por las fuerzas políticas y fuertemente interesados en las formas directas o indirectas de la participación. ${ }^{14}$

Sobre estas citadas ideas, se encuentra la noción de soberanía complexa, desarrollada por Pierre Rosanvallon cuyo pensamiento es importante en el siglo XXI, pues destaca que el voto/sufragio es tan solo una de las maneras de expresión de la voluntad popular, porque deben ser admitidas otras formas que admitan la posibilidad de que un individuo o una colectividad tome la palabra, manifieste opiniones, realice el control, mantenga la vigilancia, pronuncie juicios, en fin, participe de la vida pública. ${ }^{15}$

Norberto Bobbio afirma que se tiene una definición “mínima” de democracia, según la cual comprende que el régimen democrático debe ser entendido "primariamente como un conjunto de reglas de procedimiento para la formación de las decisiones colectivas, en que está prevista y facilitada la participación más amplia posible de los interesados."16

Según la Resolución aprobada por la Asamblea General de las Naciones Unidas el 27 de julio de 2012 nombrada El futuro que queremos:

10. Reconocemos que la democracia, la buena gobernanza y el Estado de Derecho, en los planos nacional e internacional, así como un entorno propicio, son esenciales para el desarrollo sostenible, incluido el crecimiento económico sostenido e inclusivo, el desarrollo social, la protección del medio ambiente y la erradicación de la pobreza y el hambre. Reafirmamos que para lograr nuestros objetivos de desarrollo sostenible necesitamos instituciones de todos los niveles que sean eficaces, transparentes, responsables y democráticas. ${ }^{17}$

Este tema encuentra expresión con la gobernanza europea (Libro Blanco) que impone la idea de un nuevo estilo de gobierno que tiene como base la democracia y el Estado de Derecho:

La sociedad civil desempeña un importante papel al permitir a los ciudadanos expresar sus preocupaciones y prestar servicios que respondan a las necesidades de la población. Las organizaciones que la integran movilizan a los ciudadanos y prestan su apoyo, por ejemplo, a las personas víctimas de exclusiones o discriminaciones. ${ }^{18}$

\footnotetext{
${ }^{14}$ MATEUCCI, N; PASQUINO, G. Dicionário de Políticia. Trad. Carmen C. Varriale, Gaetano Lo Mônaco, João Ferreira, Luiz Guerreiro Pinto Caçais e Renzo Dini. Brasília: UNB, v. 2, 2004. p. 889.

${ }^{15}$ ROSANVALLON, Pierre. La democratize inachevée: histoire de la souveraineté du peuple en France. Paris: Gallimard, 2000, p. 430.

${ }^{16}$ BOBBIO, Norberto. A Era dos Direitos. Rio de Janeiro: Campus, 1992, p.19.

${ }^{17} \mathrm{NACIONES} \mathrm{UNIDAS.} \mathrm{El} \mathrm{futuro} \mathrm{que} \mathrm{queremos.} \mathrm{Disponible} \mathrm{en:}$

https://rio20.un.org/sites/rio20.un.org/files/a-conf.216-l-1_spanish.pdf.pdf. Acceso em 03 de fev. 2018.

${ }^{18}$ COMISIÓN DE LA UNIÓN EUROPEA. La gobernanza europea - Un Libro Blanco. Disponible en: https://eur-lex.europa.eu/legal-content/ES/TXT/?uri=LEGISSUM\%3Al10109. Acceso em 14 de jan.2017
} 
ISSN 1981-3694

(DOI): $10.5902 / 1981369433710$

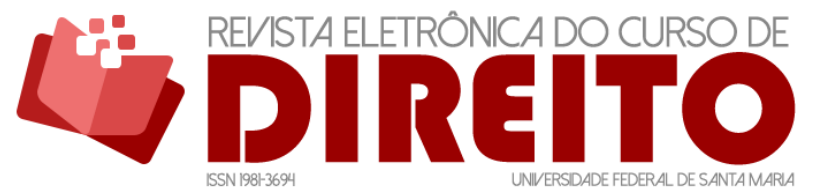

EMPRESA, DERECHOS HUMANOS Y SOCIEDAD DE LA INFORMACIÓN

Así que se existe la imposición al gobierno de un nuevo estilo que tiene como base la democracia, también tendrá cabida esta idea en las empresas por los principios de la legalidad y de la igualdad presentes en la Constitución Federal de 1988 de Brasil. Por lo tanto, si se busca la construcción de un mercado económico global más equitativo, sostenible, respetuoso a los derechos humanos e incluyente existe la imperiosa necesidad de instituciones más democráticas.

Respecto al asunto, Razquin y Ruiz de Apodaca manifiestan que la democracia participativa y la gobernanza:

entrañan la transparencia y responsabilidad en la actuación de los poderes públicos, así como la participación de la sociedad civil en los procesos de toma de decisiones, especialmente en aquellos campos caracterizados por la presencia de bienes o intereses de carácter colectivo. ${ }^{19}$

Por ello en un verdadero régimen democrático, existe la colaboración de los ciudadanos en los órganos públicos, generando la transparencia y el control en el proceso de la toma de decisiones públicas. Así se puede afirmar que para conseguir el buen gobierno es necesario el establecimiento de instrumentos de evaluación sobre el cumplimiento y respeto a los derechos humanos, reduciendo la visión cortoplacista del inversor y accionista para una más amplia y consciente de las repercusiones sociales y ambientales de sus decisiones.

\subsection{La Sociedad de la información frente a las Empresas y a los Derechos humanos}

Según Castells internet empezó en la década de 1960 por la Agencia de Proyectos de Investigación Avanzada del Departamento de Defensa de los Estados Unidos (DARPA) con la finalidad de impedir la toma del sistema norteamericano de comunicaciones por los soviéticos en el caso de una guerra nuclear. ${ }^{20}$ Como resultado de este proceso ha sido generada una red no controlada desde ningún centro y formada por millares de redes de ordenadores autónomos con innumerables maneras de conexión.

La función de la red formada por el Internet es el establecimiento de conexión en todo el mundo entre personas que cambian informaciones entre ellas. Por eso es la denominación de sociedad de la información y de la idea de la internet como instrumento informacional.

\footnotetext{
${ }^{19}$ RAZQUIN, José Antonio; RUIZ DE APODACA ESPINOSA, Ángel. Información, Participación y Justicia en Materia de Medio Ambiente: comentario sistemático a la Ley 27/2006, de 18 de julio. Pamplona: Aranzadi, 2007, p.35.

${ }^{20}$ CASTELLS, Manuel. A era da informação: economia, sociedade e cultura. Trad. Roneide Venancio Majer. São Paulo: Paz e Terra, v. 1, 2016, p. 64-65.
} 
El concepto de internet ${ }^{21}$ apareció en el contexto de la revolución tecnológica en los fines del siglo XIX después de la Segunda Guerra Mundial y generó la modificación de las estructuras sociales y del acceso a la información.

La expresión "sociedad de la información" ha pasado a ser utilizada, en los últimos años como sustitutiva al concepto complejo de "sociedad postindustrial" y como forma de transmitir el contenido específico del 'nuevo paradigma técnico económico' ${ }^{22}$

Es menester afirmar que la sociedad de la información no se limita al uso del internet, se refiere a cualquier medio de comunicación, sea presencial o no. Así que la televisión, el radio y el teléfono también son fundamentales en la caracterización de esta sociedad, es decir que

La información pasa a ser el motor de los cambios (...) La combinación de satélites, televisión, cable de fibra óptica y microordenadores presentó el mundo en un sistema unificado de conocimiento que causó la superación de las estructuras administrativas jerarquizadas y verticalizadas en dirección al movimiento horizontal de las relaciones de poder, que tiene la figura de la red, propiamente, la expresión de la nueva realidad. ${ }^{23}$

Según Barreto Junior la sociedad de la información se presenta como nuevo paradigma tecnológico, social, cultural y comportamental establecido como el marco para calificar el modelo de la sociedad influenciado por todo el aparato tecnológico. ${ }^{24}$ En el mismo sentido, Fuller establece que las nuevas tecnologías de información han empezado un cambio de naturaleza estructural en la organización social, especialmente respecto al trabajo, administración, ocio, economía y relaciones interpersonales que caracterizan lo que se denomina sociedad de la información. ${ }^{25}$

Hay que destacar el pensamiento de Morin que distingue a la sociedad de información y sociedad de conocimiento, afirmando que no estamos en una sociedad de información, pero si en una de conocimiento y comunicación, pues estamos en sociedades de informaciones

\footnotetext{
${ }^{21}$ A Internet é um sistema global de rede de computadores que possibilita a comunicação e a transferência de arquivos de uma máquina a qualquer outra máquina conectada na rede, possibilitando, assim, um intercâmbio de informações sem precedentes na história, de maneira rápida, eficiente e sem a limitação de fronteiras, culminando na criação de novos mecanismos de relacionamento. In: CORREA, Gustavo Testa. Aspectos Jurídicos da Internet. $5^{a}$ ed. Saraiva, 2010, p. 25.

22 PAESANI, L. M. (coord). O Direito na Sociedade da Informação, São Paulo: Atlas, v. 1, 2007, p.57.

${ }^{23}$ CAPELLARI, Eduardo. Tecnologias de informação e possibilidades do século XXI: por uma nova relação do estado com a cidadania. In: ROVER, Aires José (coord.). Direito, Sociedade e Informática: limites e perspectivas da vida digital. Florianópolis: Boiteux, 2000, p. 39.

${ }^{24}$ BARRETO JÚNIOR, Irineu Francisco. Atualidade do Conceito de Sociedade da Informação para a Pesquisa Jurídica. In: PAESANI, Liliana Minardi (Coord.). O Direito na Sociedade da Informação. São Paulo: Atlas, 2007, p. 62

${ }^{25}$ FULLER, Greice Patrícia. A responsabilidade social e ambiental das entidades financeiras em face do Direito Ambiental como direito humano e da sociedade da informação. Revista da Faculdade de Direito Universidade Federal de Minas Gerais, n. 71, jul/dez. 2017, p. 408-438
} 
solamente desde el punto de vista físico de la teoría de la información como son las tecnologías digitales. Y continúa afirmando que la información no es conocimiento ya que este es el resultado de la organización de la información. ${ }^{26}$

Además de la sociedad de la información se dice sobre el concepto de las redes sociales que hay una relación directa entre ellas y la sociedad en la Era de la Información:

Las redes sociales son estructuras de los agrupamientos humanos, constituidas por las interacciones que construyen los grupos sociales. En esas herramientas, esas redes son cambiadas, transformadas por la mediación de las tecnologías y, principalmente, por la apropiación de ellas para la comunicación. ${ }^{27}$

Así se dice que la sociedad pasa progresivamente a funcionar en red a través de la convergencia en escala creciente que ocurre entre productores, intermediarios y usuarios de recursos, productos y servicios de informaciones ${ }^{28}$.

En la próxima sección será analizada la sociedad de la información frente a los derechos humanos y a la actividad empresarial. Se trata de un tema importante, porque la sociedad de la información presenta como efectos la transnacionalización y el surgimiento de bloques económicos que generan un movimiento socioeconómico de integración mundial contrario al establecimiento de un Estado superior que causa “inevitables conflictos de intereses entre Estados y macroempresas"29.

\subsection{1. ¿La Sociedad de la información: una realidad perversa ante a los Derechos Humanos?}

Las nuevas tecnologías presentan un doble aspecto, es decir, de un lado aspectos positivos y del otro, negativos. De una parte, en cuanto a los primeros, se puede decir que el envío de mensajes a través de correo electrónico, en especial, en comunicaciones de larga distancia es más económica, así como el envío de mensajes que puede ser hecho con rapidez y a un número indeterminado de personas.

También se nota que la internet es un importante instrumento para la democracia, ya que hace transparente y facilita el acceso la información sobre las políticas de los diferentes

\footnotetext{
${ }^{26}$ MORIN, E. A comunicação pelo meio: teoria complexa da comunicação. Revista da Famecos n. 20, 2003, p. 8

27 RECUERO, Raquel. A conversação em Rede: comunicação mediada pelo computador e redes sociais na Internet. Porto Alegre: Sulina, 2012, p. 16.

${ }^{28}$ MIRANDA, Antonio. Sociedade da informação: globalização, identidade cultural e conteúdos. Revista Ciência da Informação, Brasília, v. 29, n. 2, p. 80-81, maio/ago. 2000, p. 78-88.

${ }^{29}$ LISBOA, Roberto Senise. Direito na Sociedade da Informação. Revista dos Tribunais, v. 847, p. 78-95, maio 2006, p.78-95.
} 
ISSN 1981-3694

(DOI): $10.5902 / 1981369433710$

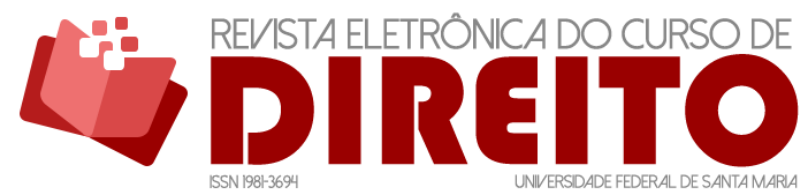

EMPRESA, DERECHOS HUMANOS Y SOCIEDAD DE LA INFORMACIÓN

gobiernos del mundo a todos y se caracteriza como mecanismo de difusión de palabras, imágenes y noticias sobre proyectos de leyes y programas gubernamentales.

De otra parte, los fallos y el mal uso cuanto al uso de internet pueden causar severos daños como la suspensión de sus comunicaciones; la práctica de delitos por los crackers; la posibilidad de recibir informaciones inexactas o de contenido discriminatorio de todo el género y la posibilidad de no ser capaz sustituir la interacción humana.

Además, se nota que la comunicación en la red surge con millares de actores interconectados que dividen, negocian y construyen contextos de interacción que unen informaciones y establecen redes sociales (v.g. Facebook, Twitter etc). ${ }^{30}$

Así que se puede decir que la sociedad de la información puede ser utilizada como instrumento de democracia inclusiva y fortalecedora del derecho a la información, sin embargo, su uso puede ser motivado por tendencias criminosas contra los bienes jurídicos del patrimonio, intimidad, vida privada, imagen, honra y otros derechos especialmente vinculados a la personalidad de la persona humana.

Por lo tanto, no es posible operar con su concepto de una manera absoluta entre los atributos de lo sagrado o lo profano, porque presenta una multiplicidad de aspectos sociales y culturales que serán los indicadores sobre la manera y objetivos del uso de las tecnologías de información.

\subsubsection{Las Empresas ante el acceso a Internet y la vulneración de los Derechos Humanos}

En este punto serán analizados los derechos humanos y la actuación de las empresas especialmente en el escenario de la sociedad de la información. Los derechos humanos en pauta serán especialmente los derechos de uso/acceso a internet, a la libertad, a la seguridad, al medio ambiente, al consumidor, a la imagen, a la intimidad y a la privacidad.

El acceso al uso de internet ha sido considerado como derecho humano, por este motivo el Consejo de Derechos Humanos de Naciones Unidas ha aprobado una resolución no vinculante afirmando la validez de los derechos humanos en entornos considerados digitales (Resolución

\footnotetext{
${ }^{30}$ RECUERO, Raquel. A conversação em Rede: comunicação mediada pelo computador e redes sociais na Internet. Porto Alegre: Sulina, 2012, p. 14.
} 
A/HRC/32/L.20) 31 . Ha referido que los derechos humanos inherentes a la libertad de expresión, la privacidad y la libertad de asociación poseen su validez y están reconocidos.

Por tanto, las prácticas de bloqueo de restricción tales como o corte del tráfico de internet o de su conexión (internet shutdown) también son considerados como violación a los derechos humanos:

El Consejo de Derechos Humanos condena inequívocamente las medidas cuyo objetivo deliberado es impedir u obstaculizar el acceso o divulgación de información en línea, vulnerando el derecho internacional de los derechos humanos, y exhorta a todos los estados a que se abstengan de adoptar estas medidas, o cesen de aplicarlas. ${ }^{32}$

Este párrafo recibió la oposición de Rusia, China, Arabia Saudita, Sudáfrica, Indonesia e India, porque afirman necesitar de formas de control para la ciudadanía.

La cuestión que toma reflexión es si a los estados y a los titulares privados de concesiones de servicios fijos y móviles y operadores del servicio de acceso a Internet existe esta exhortación, también se podría imponer la idea de que prestasen asistencia, por ejemplo, al Ministerio de Defensa y del Interior para la suspensión o corte del acceso a internet que proveen, ya que es un tipo de medida que perjudica no solo a los ciudadanos como al Estado y al sector económico o mercado.

La prohibición de comunicación es reducir la capacidad de reacción de la colectividad y de las empresas, constituyendo una amenaza a los derechos humanos.

Además, es menester que se diga que los datos informáticos (información debidamente agrupada ante criterios) son actualmente una nueva fuente de riqueza y poder. Así la forma de estructuración de la base de datos de manera sistematizada y esta potencialidad de su multiutilización para fines diversos como los económicos genera un valor, estableciendo del principio de la monetización de datos. ${ }^{33}$

Por lo tanto, la existencia de una revolución de los negocios basada en datos implantados en bases digital pasa a obtener un valor económico inmenso.

El sistema de procesamiento de datos e información que transitan en el internet (que incluye los datos sensibles, públicos, sigilosos o de cualquier otra naturaleza), a través de

\footnotetext{
31 UNITED NATIONS. GENERAL ASSEMBLY. Promotion and protection of all human rights, civil, political, economic, social and cultural rights, including the right to development. Disponible en: https: / / undocs.org/A/HRC/32/L.20. Acceso en: 04 de enero 2018. 32 UNITED NATIONS. GENERAL ASSEMBLY. Promotion and protection of all human rights, civil, political, economic, social and cultural rights, including the right to development. Disponible en: https: / / undocs.org/A/HRC/32/L.20. Acceso en: 04 de enero 2018

33 SCHMARZO, Bill. Big Data: el poder de los datos. Madrid: Anaya, 2013, p. 111.
} 
ISSN 1981-3694

(DOI): $10.5902 / 1981369433710$

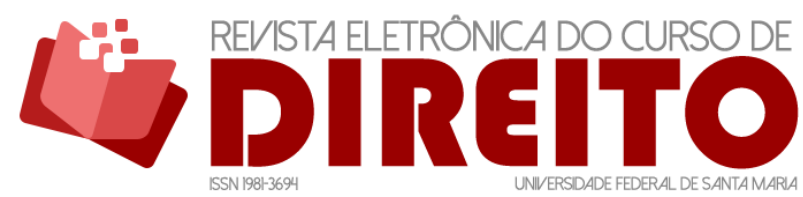

EMPRESA, DERECHOS HUMANOS Y SOCIEDAD DE LA INFORMACIÓN

herramientas tecnológicas en el modelo del Big Data, genera una selección inmensa de ellos que serán utilizados en plataformas tecnológicas en las más variadas áreas de la economía, vulnerando los principios de la privacidad e intimidad del usuario. Por lo tanto, todo lo que transita en internet, red social o intercambio de correos es transformado en datos que a partir de una tecnología apropiada de captura de ellos que serán usados de forma permanente (Big Data) con el objetivo de identificar rastros tecnológicos, tipos de comportamiento e incentivar el consumo.

$\mathrm{Y}$ este proceso realizado con el fin que las empresas puedan obtener datos para la adquisición de clientes, optimización de marketing sobre determinados productos; determinación de precios, para alcanzar una maximización de las ganancias; generar descuentos ofertas en ventas y compras; y calcular posibles riesgos en el mercado pueden generar daños a los derechos de intimidad, privacidad y libertad.

En el sistema jurídico brasileño, las leyes de protección de los datos personales, consagran el régimen de tutela de las libertades de forma individualista, según se menciona el art. 43 del Código de Defensa de Consumidor, pues establece la necesidad de generar al usuario, el acceso a la información existente en registros y datos personales y de consumo archivados en ley. ${ }^{34}$ Además, en el derecho del consumidor se exige para el tratamiento de los datos personales, el consumidor titular de ellos necesita autorizarlos.

La Ley 12.965/2014 ("Marco Civil de internet") dispone sobre el derecho de acceso a internet, pero determina la protección de los datos personales, la intimidad, la intimidad, el sigilo del flujo de las comunicaciones en internet (art. $3^{\circ}$, III; art. $7^{\circ}$, III, VII y IX; art. $8^{\circ}$ ), adoptando el principio de la autodeterminación informacional. ${ }^{35}$

Sin embargo, se nota constantemente el estado de vigilancia, ${ }^{36}$ por lo tanto se genera la inseguridad que vulnera de forma objetiva los derechos humanos inherentes a las libertades, generando una antinomia entre los intereses económicos de muchas empresas que toman el sistema del Big Data en su red informacional y de intereses privados al respecto, en especial, a la intimidad, imagen y vida privada. Hoy somos rastreados y vigilados, inducidos al consumo y sin el derecho de negar la utilización de nuestros "caminos" virtuales.

\footnotetext{
${ }^{34} \mathrm{KLEE}, \mathrm{A}$. E. L; MARTINS, G. M. A privacidade, a proteção dos dados e dos registros pessoais e a liberdade de expressão: algumas reflexões sobre o marco civil da internet no Brasil. In: A. SIMÃO FILHO, N. de LUCCA e C. R. P. LIMA (Org). Direito e Internet III. São Paulo: Quartier Latin, 2015, p. 325.

35 LIMA, C. R. P; BIONI, Bruno Ricardo. A proteção dos dados pessoais na fase de coleta: apontamentos sobre a adjetivação do consentimento implementada pelo art. 7, incisos VIII e IX do Marco Civil da Internet a partir da Human Computer Interaction e da privacy by default. em: A. SIMÃO FILHO, N. de LUCCA e C. R. P. LIMA (Org). Direito e Internet III. São Paulo: Quartier Latin, 2015, p. 267.

${ }^{36}$ BAUMAN, Z. Vigilancia líquida. Diálogos com David Lyon. Rio de Janeiro, 2013, p. 116.
} 
ISSN 1981-3694

(DOI): $10.5902 / 1981369433710$

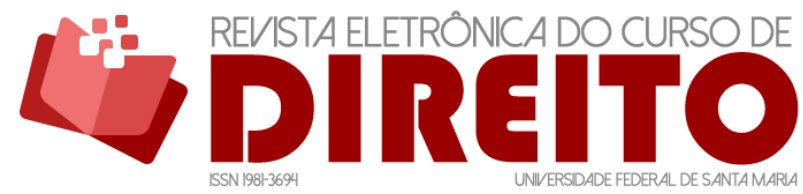

EMPRESA, DERECHOS HUMANOS Y SOCIEDAD DE LA INFORMACIÓN

Es posible también analizar la cuestión según el aspecto del fenómeno del mobbing o también denominado ciberbullying laboral. Según Leymann ${ }^{37}$, el mobbing puede ser comprendido como un fenómeno en el cual una persona o un grupo de personas ejerce violencia psicológica extrema, sistemática y habitual durante un tiempo prolongado sobre otra persona local o laboral, con la finalidad de destruir las redes de comunicación, la reputación y la capacidad laboral de la víctima ${ }^{38}$. Así que las empresas necesitan mantener una realidad interna de protección a los derechos humanos inherentes a la salud psíquica y a la honra de sus empleados, especialmente evitando acoso virtual, o sea, estimulando el uso de las tecnologías de información y comunicación para apoyar conductas deliberadas, reiteradas y agresivas a la salud psíquica del empleado (por ejemplo, en grupos de trabajo de whatsapp o facebook corporativo).

Además, el sistema empresarial posee un papel de responsabilidad ante el contexto social, ambiental y económico global. $\mathrm{Y}$ por esa razón es necesario que las empresas sean controladas según las disposiciones constitucionales (CRF/88) en sus actividades frente a su desarrollo económico y a las medidas que adopta en las políticas de gestión laboral y respecto del medio ambiente y otros derechos humanos a través de la financiación de grandes proyectos. Resulta claro que los derechos humanos ya dichos son supranacionales y presentan un núcleo pétreo centrado en la dignidad de la persona humana.

\subsection{3. ¿Dignidad empresarial: utopía frente a la Sociedad de la información y a los Derechos Humanos?}

Dignidad empresarial puede ser comprendida como el atributo de la empresa que realiza acciones en miras de proteger los derechos humanos, según UN Global Compact (el Pacto Mundial de Naciones Unidas :Global Compact) que es una iniciativa internacional que impone diez principios aceptados para promover la Responsabilidad Social Empresarial (RSE) en las áreas de derechos humanos, laborales, medio ambiente y lucha contra la corrupción en las actividades y la estrategia de negocio de empresas.

37 LEYMANN, H. Mobbing and psychological terror at workplaces. Violence and victims, 5, 1990, p. 121.

${ }^{38}$ BRASIL. TRIBUNAL REGIONAL DO TRABALHO. Acórdão de sentença que julgou improcedente os embargos de declaração. Reclamatória Ordinária $\mathrm{n}^{\circ}$ 00594-2006-011-04-00-4. Cesar Alex Oliveira Machado e Companhia de Bebidas das Américas - AMBEV Relatora: Maria Beatriz Condessa Ferreira. 19 de junho de 2006 Disponible en: https://www.trt4.jus.br/portais/trt4/sistema/consulta-processual/paginaprocesso?numeroProcesso=00594-2006-011-04-00-4 . Acceso en: 07 de feb.2018 
Por lo tanto, coexiste una complementariedad entre el tema empresas y derechos humanos, pues si hablamos del derecho a la libertad de expresión, de alimentación, de asociación u otros, estos deben estar protegidos para que existan condiciones sociales y ambientales adecuadas y se pueda legitimar el comportamiento sostenible de la empresa.

Las acciones que las empresas deben asumir en miras para ejercitar la responsabilidad social según el citado Pacto Mundial son: apoyar y respetar la protección de los derechos humanos proclamados en el ámbito internacional; asegurarse de no ser cómplices en abusos a los derechos humanos; respetar la normativa laboral individual y colectiva, incluyendo la libertad de asociación y de negociación colectiva; eliminar todas las formas de trabajo forzoso y obligatorio; abolir de forma efectiva el trabajo infantil; eliminar la discriminación con respecto al empleo y la ocupación; apoyar iniciativas para promover una mayor responsabilidad ambiental; fomentar el desarrollo y la difusión de tecnologías inofensivas para el medio ambiente y trabajar contra la corrupción.

Lo que se nota es que ante el uso lícito y el acceso del internet se puede decir que estos deberes/derechos ser protegidos por este Pacto ya que involucra el tema de derechos humanos plenamente establecido por la ONU, conforme se dijo en otro momento. Sin embargo, no se impone la forma de responsabilidad social empresarial sobre el punto referente a la protección de los usuarios de internet frente al fenómeno de la vulneración de los datos personales por empresas que desarrollan la tecnología del Big Data o de aquellas que como proveedoras de internet que no fiscalizan las prácticas de crímenes que pueden suceder en el ciberespacio.

\section{DERECHO, ECONOMÍA Y DESARROLLO, EXPERIENCIA DE LA TEORÍA A LA PRÁCTICA}

\subsection{El movimiento del Derecho y Desarrollo, una relación inseparable}

El tema del desarrollo ha sido abordado ampliamente por diferentes disciplinas del conocimiento en sus dimensión social, económico y político, en la búsqueda de encontrar soluciones y modelos que permitan fortalecer las capacidades de los estados e instituciones públicas y privadas. En cada disciplina de conocimiento, así como en el derecho se hace patente la necesidad de una intervención y coordinación con otras áreas del conocimiento, para contribuir de manera amplia y determinante en los procesos económicos, políticos y sociales. 
Autores como Trubek, ${ }^{39}$ Burgos, ${ }^{40}$ Faundez, ${ }^{41}$ entre otros, consideran que el movimiento del Derecho y Desarrollo (DyD) surgió en la década de 1960's. Teóricamente los juristas tuvieron interés por temas en América Latina, en aspectos de "seguridad" correspondiente a derechos de propiedad; "legitimidad” de las relaciones gubernamentales y ciudadanía en el desarrollo; “comunidad" relación entre el primero y segundo aspecto, y; "desigualdad" en relación a la igualdad de la ley sustantiva y distribución de la riqueza, ubicando estos temas dentro del área económica, política y social respectivamente. ${ }^{42}$

Se consideró que el movimiento de DyD continuaría su interés en América Latina de manera incremental, produciendo investigación teórica, efecto de la contribución e impulso externo de las instituciones que lo implantaron. Trubek contrastó históricamente que el movimiento presentó obstáculos, ya que cambió su enfoque hacia el "derecho económico y en la formación de abogados para empresas"; y por otra parte, se continuó con la participación de agencias internacionales como "contactos facilitadores entre sistemas legales nacionales y actores trasnacionales" ${ }^{43}$, mientras que la participación de instituciones nacionales no prosperó y su enfoque sociológico se debilitó, para centrarse en el desarrollo económico con mayor intensidad. ${ }^{44}$

En la práctica, se desarrolló a través de diferentes proyectos de investigación, orientados en los derechos humanos; ${ }^{45}$ en recomendaciones de las políticas dictadas por el Consenso de Washington y por la gran diversidad de aspectos sobre "globalización", sin embargo, el impulso más evidente y determinante fue la ayuda en la cooperación al desarrollo internacional. ${ }^{46}$ Esta ayuda se le consideró como una de las más grandes reformas legales y económicas, ofertada por

\footnotetext{
${ }^{39}$ TRUBEK, David M. Law and Development: Then and Now. Proceedings of the Annual Meeting (American Society of International Law), Are International Institutions Doing Their Job? American Society of International Law. v. 90, n. marzo 27-30, 1996, p. 223.

${ }^{40}$ BURGOS S, Germán. Derecho y desarrollo económico: de la teoría de la modernización a la Nueva Economía Institucional. Revista de Economía Institucional, v. 4, n. 7, segundo semestre. 2002, p. 175.

${ }^{41}$ FAUNDEZ, Julio. Douglass North's Theory of Institutions: Lessons for Law and Development. Hague J Rule Law. n. 8, 2016, p. 414.

42 KARST, Kenneth L; ROSENN, Keith S. Law \& Development. Law and Development in Latin America: A Case Book. Berkeley: University of California Press. 1975, p. 583.

43 TRUBEK, David M. The "Rule of Law" in Development Assistance: Past, Present, and Future. In: Y. MATSUURA. The Role Of Law In Development Past, Present And Future. Nagoya University CALE Books. 2005, p. 3.

${ }^{44}$ APARICIO, Carlos. Derecho y desarrollo económico. Revista Facultad de Derecho. Universidad de la República. Montevideo. n. 7. 1995, p. 166.

45 TRUBEK, David M. Law and Development: Then and Now. Proceedings of the Annual Meeting (American Society of International Law), Are International Institutions Doing Their Job? American Society of International Law. v. 90, n. Marzo 27-30, 1996, p. 224.

${ }^{46}$ MATSUO, Hiroshi. The Rule of Law and Economic Development: A Cause or a Result? In: Y. MATSUURA. The Role Of Law in Development Past, Present and Future. Nagoya University CALE Books. 2005, p. 59.
} 
ISSN 1981-3694

(DOI): $10.5902 / 1981369433710$

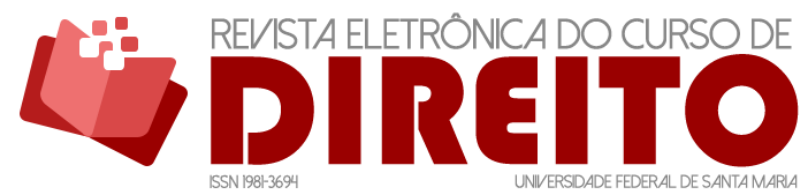

EMPRESA, DERECHOS HUMANOS Y SOCIEDAD DE LA INFORMACIÓN

gobiernos e instituciones estadounidenses hacia países de África y América Latina, así como en otros continentes. La ayuda se realizó a través del Banco Mundial, Fondo Monetario Internacional, Banco Asiático de Desarrollo, entre otros, ${ }^{47}$ a través de políticas bajo su influencia; lo que ayudaron a establecer las bases para dotar a los estados con herramientas para fortalecer y consolidar sus sistemas legales y de justicia.

Con una visión política respaldada por el derecho y dotada de legalidad, Mendelson consideró que las naciones modernas incurrían en tres etapas, una "primitiva unificación" la cual consentía primeramente fortalecerse internamente, para posteriormente implementar "políticas de industrialización" como lo fue la sustitución de importaciones para unos países, y por consiguiente, brindar mayores beneficios sociales a través "políticas de estado social benefactor", si bien, esta transición les permitió con los recursos materiales existentes desarrollarse, también requirieron de un aprendizaje en el exterior para conocer los mecanismos necesarios para generar desarrollo. ${ }^{48}$

Se puede ilustrar con el caso de los japoneses que desplazaron a Inglaterra para "estudiar armada y marina mercante"; Alemania "armada y medicina"; Francia "el derecho" y; Estados Unidos "métodos de negocios". ${ }^{49}$ Una vez consideradas naciones modernas, comerciaron y posibilitaron su apoyo a través de la cooperación internacional hacia los países en vías de desarrollo, para que los países receptores se adaptaran a los cambios en sus sistemas legales.

Por su parte, el derecho busca establecer mecanismos de control, mientras que el Desarrollo transita entre enfoques económicos e institucionales, considerados desde los años 1980s como parte de la Nueva Economía Institucional, ${ }^{50}$ que se extiende hasta nuestros días con diferentes denominaciones, desde un enfoque de "desarrollo económico de mercado", de tal forma que, la economía ubica al Derecho en un papel secundario, interviniendo de manera específica en la práctica y no a través de una disciplina capaz de contribuir en modelos de desarrollo de una manera más sólida e integradora para una adecuada gestión (visto con un

\footnotetext{
${ }^{47}$ OHNESORGE. John K. M. Developing Development Theory: Law and Development Orthodoxies and The Northeast Asian Experience. University of Pennsylvania Journal of International Law, v. 28, n. 2. 2014, p. 221.

${ }^{48}$ MENDELSON, Wallace. Law and the Development of Nations. The Journal of Politics. The University of Chicago Press on behalf of the Southern Political Science Association. v. 32, n. 2, May. p. 223-234. 1970, p. 223.

${ }^{49}$ MENDELSON, Wallace. Law and the Development of Nations. The Journal of Politics. The University of Chicago Press on behalf of the Southern Political Science Association. v. 32, n. 2, May. 1970, p. 232.

${ }^{50}$ BURGOS S, Germán. Derecho y desarrollo económico: de la teoría de la modernización a la Nueva Economía Institucional. Revista de Economía Institucional, v. 4, n. 7, segundo semestre. p. 174-199. 2002, p. 175.
} 
enfoque previsor) ante las posibles controversias legales que pudieran surgir posteriormente en las instituciones.

\section{TRANSICIÓN DEL ESTADO Y DEL MERCADO A LAS INSTITUCIONES}

La tendencia observada entre el Estado y el Mercado de una necesaria separación, estableciendo y delimitando los espacios de sus competencias en los sistemas políticos, compromete en gran medida la rectoría del Estado a favor del sector económico, se asume que el Estado debe intervenir a favor solo cuando se requiere, y generar políticas sociales. Esta visión delimitadora restada interés en la formación de estrategias y en la capacidad de los tomadores de decisiones públicos para una mayor participación. Por el fuerte impulso que tiene la economía como motor de crecimiento, el Estado trata de adaptarse a los cambios y facilitar servicios a las necesidades de la sociedad, pero se requiere de una mayor participación de las instituciones públicas con propuestas y soluciones a los problemas de índole público y privado a través de la colaboración interinstitucional.

Es importante, señalar la diferencia entre derecho al desarrollo y el derecho en el desarrollo, relaciones necesarias e indisolubles para un verdadero cambio. La primera se refiere a la relación jurídica "que reconoce a los seres humanos, a los pueblos y a los estados la facultad de obtener de la comunidad internacional y de los mismos estados el objeto de esa relación, que es justamente el desarrollo, frente al cual también se imponen deberes correlativos"; mientras que la segunda, el derecho del desarrollo o derecho en el desarrollo, debe dar certeza jurídica en los procesos a través de un "conjunto de herramientas jurídicas (declaraciones, resoluciones y tratados) e institucionales, que dan vida al desarrollo como medio". ${ }^{51}$ Por lo tanto, el DyD deberá permear en las instituciones públicas, para generar un ambiente propicio de cooperación y colaboración, ya sea a nivel internacional y/o nacionallocal.

De acuerdo con la colaboración internacional, los gobiernos y las instituciones deben encontrar modelos con capacidad para ser aplicados para solucionar problemas en diferentes contextos. North uno de los autores mayormente citados en el área económica por sus contribuciones sobre el Neoinstitucionalismo, contempla que la existencia “de las instituciones,

\footnotetext{
51 GARCÍA, Laura. El Derecho del Desarrollo como base para la construcción del Derecho al Desarrollo. Del primer decenio de las Naciones Unidas para el desarrollo (1960) a la Declaración de las Naciones Unidas para el desarrollo (1986). Int. Law: Revista Colombiana. Derecho Int. Bogotá (Colombia) n. 9: mayo. 2007, p. 238.
} 
ISSN 1981-3694

(DOI): $10.5902 / 1981369433710$

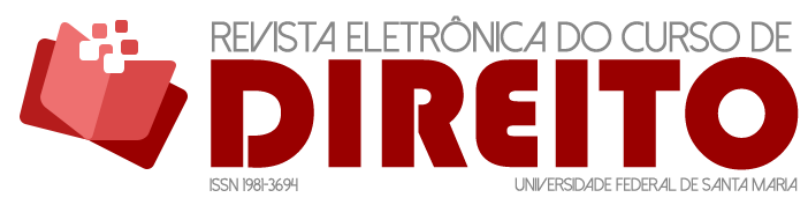

EMPRESA, DERECHOS HUMANOS Y SOCIEDAD DE LA INFORMACIÓN

incluyendo la ley, dan solución al crecimiento económico y en el proceso económico de cambio", 52 por lo tanto, las instituciones generan crecimiento y estabilidad en las economías de los países, sin embargo, la situación seria similar si su enfoque fuera en el plano social y político.

Faundez, retoma de North que "las reglas legales, son creadas, interpretadas y cambiadas por las organizaciones", ${ }^{53}$ por tal motivo, las instituciones pueden condicionar el contexto a futuro del DyD. Sin embargo, no solo la Ley y las Instituciones son determinantes hacia el desarrollo, Gomes considera que se requiere de mayores elementos, “jurídicos institucionales, como son reglas claras, protección adecuada de la propiedad privada, cumplimiento contractual y la confianza", ${ }^{54}$ cualidades centradas mayormente en la gestión, las cuales deberán garantizan el contrato social y el Estado de Derecho.

El derecho como mecanismo para generar desarrollo, deberá además "fortalecer los métodos de organización y consenso, para producir riqueza", ${ }^{55}$ así como influir de manera directa en el desarrollo tanto del ente organizacional, como de sus políticas públicas. Si bien existen poderes factuales que pueden condicionar o comprometer su actuación, el derecho deberá procedimentar y adoptar estrategias adecuadas al contexto, para que los tomadores de decisiones, bajo la expertise institucional determinen las mejores prácticas, dejando fuera intereses políticos-económicos, u de otra índole, que pongan en riesgo la capacidad del Estado y los recursos públicos.

\subsection{Experiencias del Derecho en el desarrollo}

El caso de la Transposición del Río San Francisco en Brasil en el año 2006 podría considerarse un ejemplo, por cuestiones de gran desarrollo e interés político y de Estado, al querer ampliar a través de obras de desvío las aguas del Río San Francisco hacia zonas semidesérticas del nordeste del país. Sin embargo, este proyecto "no consideraba los impactos ambientales, sociales y económicos”, por lo tanto, incumplía con la normatividad ambiental existente, por lo que el Tribunal Supremo estaba “destinado a interrumpir y revocar licencias de

\footnotetext{
52 FAUNDEZ, Julio. Douglass North's Theory of Institutions: Lessons for Law and Development. Hague J Rule Law. n. 8, 2016, p. 374.

${ }^{53}$ FAUNDEZ, Julio. Douglass North's Theory of Institutions: Lessons for Law and Development. Hague J Rule Law. n. 8, 2016, p. 401.

${ }^{54}$ GOMES, S, Mario. Repensando a Relação entre Estado, Direito e Desenvolvimento: Os Limites do Paradigma Rule Of Law e a Relevância das Alternativas Institucionais. Revista Direito GV, São Paulo v. 6 n. 1 enero - junio. 2010, p. 219.

${ }_{55}$ APARICIO, Carlos. Derecho y desarrollo económico. Revista Facultad de Derecho. Universidad de la República. Montevideo. n. 7, 1995, p. 169.
} 
ejecución del proyecto", controversia decisional por actuar tardíamente, y por la "cantidad de dinero público ejercido y medio ambiente degradado" entre otros aspectos. ${ }^{56}$

Esta situación controversial ponía en conflicto tanto el proyecto como la capacidad del Estado. La controversia pudo evitarse desde un inicio si se realizara de manera eficiente y efectiva los procedimientos antes de una aprobación, y no por canales judiciales, los cuales pueden determinar su consecución visto esto como una práctica jurídica común de la "eficacia legal a través de la eficacia judicial” donde un juez debe valorar y resolver la situación. ${ }^{57}$

Dai Kwon, reconoce la necesidad de analizar el Derecho y Desarrollo bajo la experiencia coreana, con referencia en los "abogados como agentes de cambio en el ámbito político y económico de desarrollo". ${ }^{58}$ La situación en Corea era determinante en todos los aspectos por el régimen autoritario, contraviniendo a la idea general que prima del Estado de Derecho, donde los funcionarios públicos deben someterse a la ley, y el Estado debe garantizar los derechos humanos, principalmente.

Sin embargo, todo Estado requiere de leyes y de sistemas jurídicos que brinden certeza jurídica a la sociedad y a la economía, dentro de los procesos de desarrollo económico, los cuales deben ser imparciales e inclusivos considerando a la justicia, la moral, derechos humanos, e ideas de ley superior, etc. De esta forma, se reconoce que bajo diversos contextos ya sea políticos, económicos, sociales, autoritarios o no autoritarios, la cualidad de un sistema benevolente podría determinar el desarrollo, por lo que, la práctica del derecho instrumental debe participar activamente en los procesos de cambio.

Gomes considera que las reformas legales realizadas hacia el modelo de financiamiento brasileño en los años 1960 y 1990 no lograron los resultados esperados, ${ }^{59}$ sin embargo, el Banco Nacional de Brasil en su momento continuó financiando proyectos de largo plazo y de alto riesgo si bien al Estado se ha considerado como un actor clave para el desarrollo, esta situación además ponía en riesgo al propio Estado por las fluctuaciones globales económicas, principalmente del sistema financiero internacional ante las inflación y la crisis económica, como la observada en “1981 con una tasa negativa de crecimiento del PIB en Brasil, y el incremento de la pobreza y la

\footnotetext{
${ }^{56}$ HENKES, Silviana L. A Política, o Direito e o Desenvolvimento: Um estudo sobre a transposição do rio São Francisco. Revista Direito GV, São Paulo v. 10, n. 2, Julio- Diciembre. 2014, p. 504-508.

${ }^{57}$ BURGOS S, Germán. Derecho y desarrollo económico: de la teoría de la modernización a la Nueva Economía Institucional. Revista de Economía Institucional, v. 4, n. 7, segundo semestre. 2002, p. 189.

${ }^{58}$ DAI KWON, Choi. Law and Development: The Korean Experience. Seoul Law Journal. v. 52 n. 3 septiembre. 2011, p. 39-42.

59 GOMES, S, Mario. Repensando a Relação entre Estado, Direito e Desenvolvimento: Os Limites do Paradigma Rule Of Law e a Relevância das Alternativas Institucionais. Revista Direito GV, São Paulo v. 6 n. 1 enero - junio. 2010, p. 236-247.
} 
ISSN 1981-3694

(DOI): $10.5902 / 1981369433710$

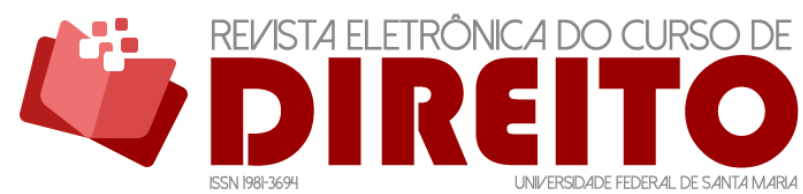

EMPRESA, DERECHOS HUMANOS Y SOCIEDAD DE LA INFORMACIÓN

desigualdad". ${ }^{60}$ La situación que realmente se buscaba, era una mayor participación de instituciones públicas y privadas nacionales para poder financiar a las pequeñas y medianas empresas y a los hogares más pobres, liberándose el Estado de cargas que podían ser asumidas por entidades privadas, y de esta forma financiar proyectos sociales.

Como pudo observarse en los tres casos anteriores referente al Río San Francisco, el caso coreano, y al modelo de financiamiento en Brasil, las reformas legales y el sistema pueden promover o restringir el desarrollo en diferentes áreas (social, económica y política), pero se requiere de un análisis multidisciplinario previo que garantice lo que debe implantarse, en qué tiempo y forma, para realmente beneficiar los intereses públicos tanto comunes e individuales, sin poner en riesgo los recursos tanto públicos como privados.

\section{DESARROLLO ECONÓMICO}

Si retomamos al sector económico como el motor de crecimiento de las economías, podríamos establecer al derecho como un mecanismo para garantizar el Desarrollo. Respecto desarrollo económico, Dabat, Rivera et al., consideran importante el tema "cambio tecnológico y cambio estructural”, el primero contempla fortalecer las capacidades de producción para ser aplicado a productos y procesos, considerado esto, parte del aprendizaje por la transferencia del conocimiento, aunado a los factores institucionales y económicos comúnmente conocidos y establecidos relacionados a la normatividad, el capital, trabajo, recurso humano, etc,; mientras que el segundo hace alusión de entender "los cambios estructurales de la economía mundial" desde un plano político, económico y social, para aprovechar los máximos beneficios, identificando los momentos adecuados, espacios y formas de gestión para una mayor producción y comercio. ${ }^{61}$

A demás de lo anterior, nos recuerda, la existencia de empresas con mayor experiencia, y evolución, en específico en la manufactura a través de las cadenas globales de producción en los países asiáticos, que son alta y tecnológicamente desarrolladas, en comparación de otras empresas en otros países, los cuales se estancan o desaparecen, sin embargo, al considerar el

\footnotetext{
${ }^{60}$ GANUZA, Enrique; LEÓN, Arturo; SAUMA, Pablo. Brasil en Gasto público en servicios sociales básicos en América Latina y el Caribe. Análisis desde la perspectiva de la Iniciativa 20/20. Naciones Unidas, Revista CEPAL. UNICEF. 1999, p. 171.

${ }^{61}$ DABAT, Alejandro; RIVERA R, Miguel Ángel; SZTULWARK, Sebastián. Rentas económicas en el marco de la globalización: desarrollo y aprendizaje. v. 38, n. 151. octubre-diciembre, 2007, p. 17-32.
} 
ISSN 1981-3694

(DOI): $10.5902 / 1981369433710$

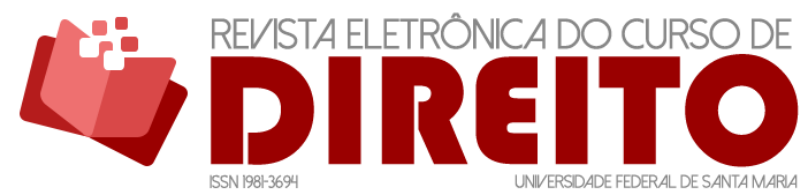

EMPRESA, DERECHOS HUMANOS Y SOCIEDAD DE LA INFORMACIÓN

cambio estructural a su favor, les deberá motivar para insertarse de una manera más ágil a las redes globales de producción.

Por lo tanto, el momento actual de cambio que perciben los autores, lo consideran oportuno para los países en vías de desarrollo, y si no es entendido, difícilmente podrán aprovecharse e insertarse en las cadenas globales en su etapa de expansión y complejidad. Por ello, el cambio estructural, más los factores de producción en el caso de América Latina, por gran cantidad de recursos naturales y su mano de obra cualificada más los productos de mayor valor agregado en conjunto, les permitirá evolucionar e industrializarse para proveer productos, servicios y tecnología, así como también ubicar nuevos mercados, considerando el escalonamiento productivo como parte del avance que se espera lograr tanto en crecimiento como en desarrollo.

Por su parte, Burgos señala que en países la propiedad de la tierra está sujeta a "fines sociales y ambientales", ${ }^{62}$ por lo que el Estado bajo aplicación de la Ley, deberá observar las condiciones para su correcta explotación económica, sin interponer intereses, atendiendo las recomendaciones de organizaciones dedicadas a la protección del medioambiente y el desarrollo sustentable.

\subsection{Cadenas Globales de Producción}

Kosacoff y López identifican que una de las potencialidades que tienen las empresas nacionales para insertarse a las cadenas globales de valor es la "calidad del ambiente institucional", ${ }^{63}$ el cual da certeza jurídica para terciarizar procesos, diversificar inversiones, expandirse en mercados, generando nuevas relaciones comerciales, pero la situación del ambiente institucional le corresponde al Estado de garantizar a través del derecho un clima de estabilidad política, social, económica y de justicia, basado en las leyes y en un Estado de Derecho, para que el sector privado pueda invertir con confianza, sin considerar su inversión en situación de riesgo.

La Inversión Extranjera Directa, ha traído beneficios para muchos países, sin embargo, un tema que pudiera parecer controversial, es el considerado por Kosacoff y López, al asumir que la IED "se dirigió a explotar a los mercados internos de los países receptores, sin buscar

\footnotetext{
62 BURGOS S, Germán. Derecho y desarrollo económico: de la teoría de la modernización a la Nueva Economía Institucional. Revista de Economía Institucional, v. 4, n. 7, segundo semestre. 2002, p. 192. ${ }^{63}$ KOSACOFF, Bernardo; LÓPEZ, Andrés. América Latina y las Cadenas Globales de Valor: debilidades y potencialidades. GCG Georgetown University - Universia. v. 2, n. 1. 2008, p. 29.
} 
ISSN 1981-3694

(DOI): $10.5902 / 1981369433710$

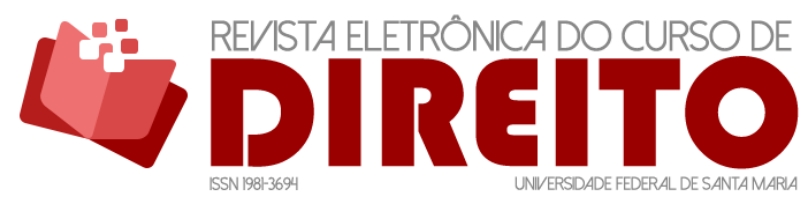

EMPRESA, DERECHOS HUMANOS Y SOCIEDAD DE LA INFORMACIÓN

activamente la integración en las Cadenas Globales de Valor", ${ }^{64}$ por lo tanto, el objeto primario correspondió a maximizar la producción creando nuevas empresas, y posteriormente terciarizar procesos productivos subcontratando a otras. Sin embargo, asumir que el flujo de recursos económicos (por vía de la IED) podría o debería cambiar la estructura productiva de las empresas en los países receptores, supone una exigencia a la que no todas las empresas estarían dispuestas a asumir.

Por lo tanto, mientras más claro sea el ambiente institucional y la práctica jurídica evolucione, se generará un crecimiento y mejor desarrollo traducido en una mejorar las condiciones sociales, pero si esta situación no se adecua al contexto, se corre el riesgo de perder inversiones tanto nacionales como extranjeras, para ubicarse en otros países donde las inversiones sean más rentables para sus economías.

De acuerdo a lo anterior, se podría considerar el ejemplo retomado por Blyde del consorcio Apex en Brasil, cuya normatividad no estaba acondicionada para que los consorcios fueran regulados, por lo cual, la figura legal que mejor legalizaba era la de una organización sin fines de lucro pero esta situación a las empresas no les brindaba claridad legal ni física, por lo que optaban por realizar en lo particular relaciones privadas con alguna empresa del consorcio. ${ }^{65}$ Por lo tanto, la práctica jurídica deberá intervenir reconociendo y legalizando a nivel interno las modalidades que se requieren, para dotar de ayuda a las empresas nacionales en su forma de organización y trabajo, para atender la demanda global.

\section{ACUERDOS E INSTITUCIONES INTERNACIONALES}

En aspecto institucional con relevancia para el derecho, son los acuerdos internacionales, ya que establece las bases para su correcta dinámica en diferentes áreas en gran alcance. Se generan relaciones, se incluyen nuevos miembros y cuando la situación lo amerita, se transita a la conformación de bloques o uniones regionales, las cuales tienden a un mayor número de ventajas para las partes, como es la "fragmentación de la producción en toda la región". ${ }^{66}$ Por lo

\footnotetext{
${ }^{64}$ KOSACOFF, Bernardo; LÓPEZ, Andrés. América Latina y las Cadenas Globales de Valor: debilidades y potencialidades. GCG Georgetown University - Universia. v. 2, n. 1. 2008, p. 25.

${ }^{65}$ BLYDE, Juan S. (coord.) Fábricas Sincronizadas: América Latina y el Caribe en la Era de las Cadenas Globales de Valor. Informe Especial sobre Integración y Comercio. Banco Interamericano de Desarrollo. 2014, p. 87.

${ }^{66}$ BLYDE, Juan S. (coord.) Fábricas Sincronizadas: América Latina y el Caribe en la Era de las Cadenas Globales de Valor. Informe Especial sobre Integración y Comercio. Banco Interamericano de Desarrollo. 2014, p. 60.
} 
tanto, se intercambian bienes, servicios y se facilitan el movimiento de personas, incrementando las redes y transfiriendo tecnológica, pero se requiere de infraestructura adecuada para dar respuesta inmediata.

Por otra parte, a pesar de la existencia de instituciones internacionales como la Cámara de Comercio Internacional $(\mathrm{CCl})$ que brindan modelos de contratos y facilitan el entendimiento a través de los "términos internacionales de contrato" (comúnmente llamados intercoms) para las transacciones privadas internacionales, las cuales contribuyen a reducir las posibles controversias internacionales entre privados, en la práctica, las empresas deciden el mejor modelo legal, ya sea utilizando alguno de la $\mathrm{CCl}$ o por contratos privados que no tienen un respaldo de instituciones dedicadas a revisar el éxito o las fallas contractuales.

Si retomamos el tema de las cadenas globales de producción, encontramos retos a los cuales los estados y las empresas en América Latina tienen que solventar. Tanto la revisión y adecuación de la normatividad nacional e internacional que les legitime para estar fuertemente constituidas; así como adoptar modelos de relaciones contractuales entre diversas empresas de diferentes países y diferentes sistemas legales y jurídicos. Actualmente hay una gran cantidad de acuerdos comerciales en cada uno de los países, sin embargo, se deberá considerar si estos están dando los resultados esperados, o si existe la necesidad de replantearse una diferente integración u asociación entre países, para que pueda redituar en mayores beneficios a cada una de las partes.

La transferencia de conocimiento forma parte del aprendizaje, por ello, han existido algunos programas gubernamentales exitosos promovidos por los gobiernos para acelerar el desarrollo de las empresas nacionales, reduciendo la curva marginal de aprendizaje. Los programas pueden considerarse como reglas formales de promoción, obligación o limitación, de las cuales las empresas se pueden valer.

El caso del programa de Irlanda de 1985 “National Linkages Program” su objetivo era de evaluar y mejorar la capacidad de proveedores en las áreas "técnicas, financieras, gestión, sistema de calidad, fianzas y mercadeo"; así como también el "Programa de Mejora de la Industria Local en Singapur” en 1986, donde las compañías “multinacionales capacitaban a las empresas locales", ${ }^{67}$ por lo tanto, el aprendizaje fue directo, en el primero fortaleció sus capacidades, mientras que el segundo, fomentó beneficios para y por las compañías extranjeras. En el caso mexicano, solo se trabajó bajo las "bolsas de subcontratación" y que hasta nuestros

${ }^{67}$ BLYDE, Juan S. (coord.) Fábricas Sincronizadas: América Latina y el Caribe en la Era de las Cadenas Globales de Valor. Informe Especial sobre Integración y Comercio. Banco Interamericano de Desarrollo. 2014, p. 129-132. 
ISSN 1981-3694

(DOI): $10.5902 / 1981369433710$

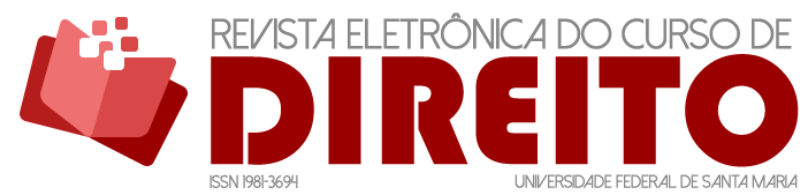

EMPRESA, DERECHOS HUMANOS Y SOCIEDAD DE LA INFORMACIÓN

días se continúa ofertando directorios de empresas proveedoras nacionales. La aprendizaje y maduración de las empresas mexicanas fue indirecto, y se potencia con programas de ferias de negocios internacionales para poder acceder a nuevos proveedores o mercados extranjeros.

\subsection{La Protección de los Derechos Humanos en las Cadenas Globales de Producción}

En el tema de las cadenas globales de producción o cadenas de suministro, el debate se centra mayormente en las empresas que la integran; en su ubicación en la línea de producción, y; la modalidad que desarrollan, sin embargo, son las personas como capital humano las que hace posible su realización, por lo tanto, el derecho deberá protegerlos ante circunstancias efecto de las necesidades de la demanda global, la cual pone en riesgo sus derechos humanos.

Según el Director Regional de la Organización Internacional del Trabajo (OIT) para América Latina y el Caribe, las "cadenas mundiales de suministros generan más de 450 millones de empleo al nivel global", esta cantidad representa un $6.1 \%$ del total de la población mundial durante el 2015.68 Para la mayoría de las personas, las cadenas de suministros son una oportunidad laboral con buenas condiciones, pero para otras personas sucede lo contrario. Según las estimaciones de OIT “21 millones son víctimas de trabajo forzado”, el Derecho internacional lo considera como "un delito y los países lo prohíben en sus legislaciones" 69 sin embargo, se la incapacidad de las autoridades judiciales nacionales para poder corregir dichos problemas.

Ante esta situación de vulnerabilidad, el trabajador difícilmente puede corregir los abusos que sufre, por el acoso de perder el trabajo como única opción, y por la incapacidad de las instituciones antes mencionado, por lo tanto, no tienden a denunciar, en este grupo se ubican las mujeres, trabajadores migrantes y niños, pero la situación cambia dependiendo el contexto geográfico y la diversidad de empresas a las que pueden acceder. Por lo tanto, los gobiernos y las organizaciones tienen una tarea compleja, para vigilar y sancionar aquellas empresas que pongan en riesgo la calidad de vida y las condiciones laborales.

A través de la OIT los gobiernos se comprometen para promover la justicia social y un trabajo decente en sus países, así como también para fortalecer sus legislaciones nacionales

68 ORGANIZACIÓN INTERNACIONAL DEL TRABAJO. 21 millones de personas son víctimas de trabajo forzoso. Promover el empleo, proteger a las personas. Noticia del 1 de junio de 2012. 2012. Disponible en: http://ilo.org/global/about-the-ilo/newsroom/news/WCMS_181993/lang-es/index.htm. Acceso en: 18 de mar. 2017, p. 1.

${ }^{69}$ ORGANIZACIÓN INTERNACIONAL DEL TRABAJO. 21 millones de personas son víctimas de trabajo forzoso. Promover el empleo, proteger a las personas. Noticia del 1 de junio de 2012. 2012. Disponible en: http://ilo.org/global/about-the-ilo/newsroom/news/WCMS_181993/lang-es/index.htm. Acceso en: 18 de mar. 2017, p. 1. 
sobre el Derecho del trabajo. En el preámbulo de la Constitución de la OIT con última reforma en 1974, de base, se señala la existencia sobre las condiciones laborales que sufren las personas, tales como "injustas, de miseria y de privaciones", ${ }^{70}$ aunado hasta nuestros días se agregan recomendaciones y directrices a las cuales los gobiernos deben convenir, por lo tanto, en el preámbulo se contempla lo siguiente con el fin de contrarrestarlas:

[...]es urgente mejorar dichas condiciones, concerniente a reglamentación de las horas de trabajo, fijación de la duración máxima de la jornada y de la semana de trabajo, contratación de la mano de obra, lucha contra el desempleo, garantía de un salario vital adecuado, protección del trabajador contra las enfermedades, sean o no profesionales, y contra los accidentes del trabajo, protección de los niños, de los adolescentes y de las mujeres, pensiones de vejez y de invalidez, protección de los intereses de los trabajadores ocupados en el extranjero, reconocimiento del principio de salario igual por un trabajo de igual valor y del principio de libertad sindical, organización de la enseñanza profesional y técnica y otras medidas análogas. ${ }^{71}$

Como puede observarse, para la promoción y protección de los derechos humanos en el área laboral, el derecho tiene una tarea trascendental, tanto a nivel interno como internacional, al igual que las instituciones judiciales y/o tribunales, ya que la diversidad de temas según el preámbulo, un trabajador está expuesto ante adversidades sin importar el lugar geográfico, ya que los abusos pueden encontrarse en alguna empresas en particular, en relación a temas como la duración de la jornada laboral, sus derechos sociales y su seguridad.

Existe una gran cantidad de referencias disponibles sobre las condiciones en que viven los trabajadores que son explotados por empresas, pero el preámbulo antes mencionado, nos da un panorama amplio, que no es necesario exponer, pero se puede traducir en diferentes contextos y en diferente intensidad, por lo tanto, se requiere de mayores investigaciones específicas que los aborden para subsanar los grandes problemas a los que se enfrenta la población que puede estar en situación de riesgo.

70 Cfr. ORGANIZACIÓN INTERNACIONAL DEL TRABAJO. Preámbulo de la Constitución de la Organización Internacional del Trabajo enmendada en 1974. 2008. Disponible en:

https://www.ilo.org/dyn/normlex/es/f?p=NORMLEXPUB:62:0::NO::P62_LIST_ENTRIE_ID:2453907. Acceso en: 18 de mar. 2017, p. 1.

71 ORGANIZACIÓN INTERNACIONAL DEL TRABAJO. Constitución de la Organización Internacional del

Trabajo. enmendada en 1974. 2008. Disponible en: https://www.ilo.org/dyn/normlex/es/f?p=NORMLEXPUB:62:0::NO::P62_LIST_ENTRIE_ID:2453907. Acceso en: 18 de mar. 2017, p. 1. 


\section{CONCLUSIÓN}

A continuación, se presentan las conclusiones sobre el tema de empresa, derechos humanos y sociedad de la Información ante el desarrollo económico en el siglo XXI y se complementa de las áreas de estudio sobre el derecho, economía y desarrollo, como resultado del análisis crítico, jurídico y filosófico, cuyo objetivo pretende contribuir a ser aplicadas en la práctica.

Referente a los temas tratados, los derechos humanos no son un concepto unívoco, pero es posible que se destaque que son exigencias de dignidad, libertad e igualdad humana; y que para que el mercado económico sea sostenible e incluyente e imponga el respeto de ellos.

Más allá de esta imposición, se menciona la idea del capitalismo humanista que tiene como bases, a través de las enseñanzas de John Locke, la necesidad que el régimen capitalista retome los derechos humanos en todas sus dimensiones para la satisfacer el principio de la dignidad de la persona humana.

Los derechos humanos, la actividad empresarial y el tema de la sociedad de la información presentan relación. Al mismo tiempo que esta última trae ventajas como la posibilidad de participación de los ciudadanos y empresas en la sociedad, también exhibe deberes. A este contexto se puede agregar la idea de que solo en un régimen democrático habrá el buen gobierno y la responsabilidad empresarial a los derechos humanos.

La sociedad de la información es un importante instrumento para traer mejoras a las comunicaciones, promover la información rápida, transnacional y económica, difusión de palabras y noticias gubernamentales, inclusión digital en el tema de educación. Sin embargo, puede ser utilizado a través de personas físicas o jurídicas (empresas) para la práctica de crímenes contra el patrimonio, imagen, honra, intimidad y vida privada. Además, se defiende el pensamiento de que a la empresa es prohibida la práctica de impedir el acceso a internet sea por parte de sus funcionarios o sea para todos los usuarios de un determinado proveedor, ya que en esta situación se tiene la vulneración de un derecho humano así establecido por la ONU. Si no fuera suficiente esta prohibición a las empresas, aún se preconiza que el uso de la tecnología de Big Data genera la violación a las libertades de intimidad y privacidad.

A pesar de la posibilidad de los usos ilícitos por parte de las empresas de las nuevas tecnologías de información aún se puede creer en la dignidad empresarial como un atributo de las empresas que observan la responsabilidad social empresarial (RSE) en materia de derechos 
ISSN 1981-3694

(DOI): $10.5902 / 1981369433710$

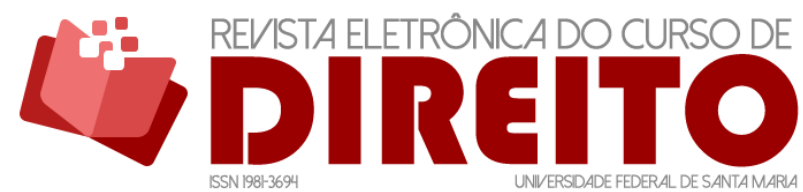

EMPRESA, DERECHOS HUMANOS Y SOCIEDAD DE LA INFORMACIÓN

humanos, pero aún se permanecerán discusiones sobre el uso de internet en prácticas criminales o para manipulación del mercado frente a demandas productivas (fenómeno de Big Data).

En cuanto a las áreas de interés revisadas, con una visión holística se manifiesta la necesidad de que el derecho y la academia deba participar activamente en el desarrollo y en la gestión pública administrativa y empresarial, ya sea a través de investigaciones aplicadas, asesoría en foros democráticos, o en la planeación de las políticas públicas y privadas, para fortalecer e impactar de manera directa e indirecta la gestión, mejorando las condiciones de la sociedad.

Es importante reconocer el rol que tiene la sociedad de la información, por el bagaje de conocimientos acumulados que se encuentran disponibles en los medios de comunicación, al que los tomadores de decisiones deberían considerar de manera permanente, sin embargo, no siempre su acceso es disponible, o su uso es limitado, por ello, se recomienda que las Instituciones Públicas y Privadas inviertan e intervengan en los procesos para facilitar la comunicación, y el uso de medios para generar estratégicas en políticas públicas eficaces.

Equilibrar los aspectos económicos, políticos y sociales, es una tarea compleja y obligatoria para las instituciones del desarrollo, máxime si se trata de recursos públicos para ser ejercidos. La experiencia teórica y práctica que se genera, deberá servir de base para todos los gobiernos que se preocupan por agilizar el desarrollo en todos los contextos.

En cada periodo de gobierno, la situación puede cambiar y se espera que los cambios sean positivos, sin embargo, cada administrador de "la casa pública" o de la actividad empresarial, de acuerdo, a como se comporte el Estado o el Mercado, este deberá encontrar la mejor estrategia, aunado a las limitaciones que se tienen ya sea en recurso, conocimiento o infraestructura.

Las herramientas jurídicas que promueve el derecho para el desarrollo ya sean los acuerdos de libre comercio, las organizaciones internacionales o uniones entre países, en colaboración con la economía política de desarrollo (EPD) como disciplinas integradoras y multidisciplinarias, tienen un gran potencial para proteger los derechos humanos a través del entramado de políticas y de transacciones desde un nivel global a uno local.

Por ello, en este artículo se puso énfasis la relación entre diferentes temas y áreas de estudio, haciendo plausible, un esfuerzo de no dejar fuera elementos que puedan valorarse para futuras investigaciones que busquen cambios a los que aspira la sociedad. 


\section{REFERENCIAS}

APARICIO, Carlos. Derecho y desarrollo económico, Revista Facultad de Derecho. Universidad de la República. Montevideo. n. 7 p. 161-184. 1995.

ASAMBLEA GENERAL. Promoción y protección de todos los derechos humanos, civiles, políticos, económicos, sociales y culturales, incluido el derecho al desarrollo. Consejo de Derechos Humanos. Naciones Unidas. 17 período de sesiones. 2011.

BAUMAN, Z. Vigilância líquida. Diálogos com David Lyon. Rio de Janeiro, 2013.

BARRETO JÚNIOR, Irineu Francisco. Atualidade do Conceito de Sociedade da Informação para a Pesquisa Jurídica. In: PAESANI, Liliana Minardi (Coord.). O Direito na Sociedade da Informação. São Paulo: Atlas, 2007.

BLYDE, Juan S. Fábricas Sincronizadas:América Latina y el Caribe en la Era de las Cadenas Globales de Valor. Banco Interamericano de Desarrollo. Informe Especial sobre Integración y Comercio. p. 186. 2014.

BOBBIO, N. A Era dos Direitos. Rio de Janeiro: Campus, 1992.

BRASIL, Constituição Federal (1988). Constituição da República Federativa do Brasil. Diário Oficial da União. Brasília. DF. 5 out. 1988. Disponible en:

http://www.planalto.gov.br/ccivil_03/constituicao/constituicao.htm .

Acceso en: 25 de ago. 2018.

BURGOS S, Germán. Derecho y desarrollo económico: de la teoría de la modernización a la Nueva Economía Institucional. Revista de Economía Institucional, v. 4, n. 7, segundo semestre. p. 174-199. 2002.

CANOTILHO, J.J. Gomes. Direito Constitucional. Coimbra: Almedina, 1992.

CAPELLARI, Eduardo. Tecnologias de informação e possibilidades do século XXI: por uma nova relação do estado com a cidadania. In: ROVER, Aires José (coord.). Direito, Sociedade e Informática: limites e perspectivas da vida digital. Florianópolis: Boiteux, 2000, p. 39.

CASTELLS, Manuel. A era da informação: economia, sociedade e cultura, Trad. Roneide Venancio Majer. São Paulo: Paz e Terra, v. 1. 2016.

COMISIÓN DE LA UNIÓN EUROPEA. La gobernanza europea:Un Libro Blanco. Disponible en: https://eur-lex.europa.eu/legal-content/ES/TXT/?uri=LEGISSUM\%3Al10109. Acceso en: 14 de jan.2017.

COMPARATO, Fábio Konder. Ética. São Paulo: Companhia das Letras, 2006.

CORREA, Gustavo Testa. Aspectos Jurídicos da Internet. 5a ed. Saraiva, 2010. 
DABAT, Alejandro; RIVERA R, Miguel Ángel; SZTULWARK, Sebastián. Rentas económicas en el marco de la globalización: desarrollo y aprendizaje. v. 38, n. 151. octubre-diciembre, 2007.

DAI-KWON, Choi. Law and Development: The Korean Experience. Seoul Law Journal. v. 52 n. 3 September. p. 37-62. 2011.

DE JONGE, A. Transnacional Corporations and International Law. Accountability in the Global Business Environment. Cheltenham-Northampton: Edward Edgar, 2011.

FAUNDEZ, Julio. Douglass North's Theory of Institutions: Lessons for Law and Development. Hague J Rule Law. n. 8, p. 373-419. 2016.

FULLER, Greice Patrícia. A responsabilidade social e ambiental das entidades financeiras em face do Direito Ambiental como direito humano e da sociedade da informação. Revista da Faculdade de Direito Universidade Federal de Minas Gerais, n. 71, jul/dez.2017.

FULLER, Greice Patricia. A contemporaneidade do pensamento de John Locke no contexto do século XXI. Revista de Direito Constitucional e Internacional. São Paulo: Revista dos Tribunais, 2004.

GADREY, Jean; JANY-CATRICE, Florence. Os novos indicadores de riqueza. São Paulo: Senac, 2006.

GANUZA, Enrique; LEÓN, Arturo; SAUMA, Pablo. Brasil en Gasto público en servicios sociales básicos en América Latina y el Caribe. Análisis desde la perspectiva de la Iniciativa 20/20. Naciones Unidas, Revista CEPAL. UNICEF. p. 758. 1999.

GARCÍA, Laura. El Derecho del Desarrollo como base para la construcción del Derecho al Desarrollo. Del primer decenio de las Naciones Unidas para el desarrollo (1960) a la Declaración de las Naciones Unidas para el desarrollo (1986). Int. Law: Revista Colombiana. Derecho Int. Bogotá (Colombia) n. 9: p. 235-272, mayo. 2007.

GOMES, Shapiro Mario. Repensando a Relação entre Estado, Direito e Desenvolvimento: Os Limites do Paradigma Rule Of Law e a Relevância das Alternativas Institucionais. Revista Direito GV, São Paulo v. 6 n. 1, Jan-Jun., p. 213-252.

HENKES, Silviana L. A Política, o Direito e o Desenvolvimento: Um Estudo Sobre A Transposição do Rio São Francisco. Revista Direito GV, São Paulo v. 10, n. 2, Jul-Dez. p. 497-534. 2014

JUNG, C.G. Os arquétipos e o inconsciente coletivo. Rio de Janeiro: Vozes, 2008.

KARST, Kenneth L; ROSENN, Keith S. Law \& Development. Law and Development in Latin America: A Case Book. Berkeley: University of California Press. p. 738. 1975.

KLEE, A. E. L; MARTINS, G. M. A privacidade, a proteção dos dados e dos registros pessoais e a liberdade de expressão: algumas reflexões sobre o marco civil da internet no Brasil. In: A. SIMÃO FILHO, N. de LUCCA e C. R. P. LIMA (Org). Direito e Internet III. São Paulo: Quartier Latin, 2015. 
KOSACOFF, Bernardo; LÓPEZ, Andrés. América Latina y las Cadenas Globales de Valor: debilidades y potencialidades. GCG Georgetown University - Universia. v. 2, n. 1. p. 18-32. 2008.

LEYMANN, H. Mobbing and psychological terror at workplaces. Violence and victims, 5, 1990.

LIMA, C. R. P; BIONI, Bruno Ricardo. A proteção dos dados pessoais na fase de coleta: apontamentos sobre a adjetivação do consentimento implementada pelo art. 7, incisos VIII e IX do Marco Civil da Internet a partir da Human Computer Interaction e da privacy by default. In:A. SIMÃO FILHO, N. de LUCCA e C. R. P. LIMA (Org). Direito e Internet III. São Paulo: Quartier Latin, 2015.

LOCKE, John. O Segundo Tratado sobre o Governo Civil. São Paulo: Edipro, 2014.

MARTINEZ, Gutemberg. Humanismo e economia: ética e responsabilidade, São Paulo: Bem Comum, n. 84. 2005.

MATEUCCI, N; PASQUINO, G.. Dicionário de Políticia. Trad. Carmen C. Varriale, Gaetano Lo Mônaco, João Ferreira, Luiz Guerreiro Pinto Caçais e Renzo Dini. Brasília: UNB, v. 2, 2004.

MATSUO, Hiroshi. The Rule of Law and Economic Development: A Cause or a Result? En Y. MATSUURA. The Role Of Law in Development Past, Present and Future. Nagoya University CALE Books. 2005.

MENDELSON, Wallace. Law and the Development of Nations. The Journal of Politics. The University of Chicago Press on behalf of the Southern Political Science Association. v. 32, n. 2, May. p. 223-234. 1970.

MIRANDA, Antonio. Sociedade da informação: globalização, identidade cultural e conteúdos. Revista Ciência da Informação, Brasília, v. 29, n. 2, p. 80-81, maio/ago. 2000

MORIN, E. A comunicação pelo meio: teoria complexa da comunicação. Revista da Famecos n. 20, 2003.

MORROW, P. A Pocket guide to Corporate Governance. Bold Institute, p. 4. 2015. Disponible en: http://corporate-responsibility.org/wp-content/uploads/2015/pocket-guide-to-corporategovernance.pdf. Acceso en: 26 de feb. 2017.

NACIONES UNIDAS. El futuro que queremos. Disponible em: https://rio20.un.org/sites/rio20.un.org/files/a-conf.216-l-1_spanish.pdf.pdf. Acceso en: 03 de ene. 2018.

LISBOA, Roberto Senise. Direito na Sociedade da Informação. Revista dos Tribunais, v. 847, maio 2006.

OHNESORGE. John K. M. Developing Development Theory: Law and Development Orthodoxies and The Northeast Asian Experience. University of Pennsylvania Journal of International Law, v. 28, n. 2. p. 219-308. 2014. 
ORGANIZACIÓN INTERNACIONAL DEL TRABAJO. Constitución de la Organización Internacional del Trabajo. enmendada en 1974. 2017. Disponible en:

http://www.ilo.org/dyn/normlex/es/f?p=1000:62:0::NO:62:P62_LIST_ENTRIE_ID:2453907:NO. Acceso en: 18 de mar. 2017.

ORGANIZACIÓN INTERNACIONAL DEL TRABAJO. 21 millones de personas son víctimas de trabajo forzoso. Promover el empleo, proteger a las personas. Noticia del 1 de junio de 2012. 2012. Disponible en: http://ilo.org/global/about-the-ilo/newsroom/news/WCMS_181993/lang-es/index.htm Acceso en: 18 de mar. 2017.

ORGANIZACIÓN INTERNACIONAL DEL TRABAJO. Cadenas mundiales de suministro y empleo en América Latina y el Caribe. Promover el empleo, proteger a las personas. Noticia del $21 \mathrm{de}$ agosto de 2015. 2015. Disponible en: http://www.ilo.org/americas/sala-deprensa/WCMS_393912/lang-es/index.htm . Acceso en: 24 de feb. 2017.

PAESANI, L. M (Coord). O Direito na Sociedade da Informação, São Paulo: Atlas, v. 1. 2007. PEREZ LUÑO, A. E. Los Derechos Fundamentales. Madrid: Tecnos, 2004.

RAZQUIN, José Antonio; RUIZ DE APODACA ESPINOSA, Ángel. Información, Participación y Justicia en Materia de Medio Ambiente: comentario sistemático a la Ley $27 / 2006$, de 18 de julio. Pamplona: Aranzadi S.A., 2007.

RECUERO, Raquel. A conversação em Rede: comunicação mediada pelo computador e redes sociais na Internet. Porto Alegre: Sulina, 2012.

ROSANVALLON, Pierre. La democratize inachevée: histoire de la souveraineté du peuple en France. Paris: Gallimard, 2000.

SCHMARZO, Bill. Big Data: el poder de los datos. Madrid: Anaya, 2013.

TABRA OCHOA, E. P. Solidaridad y Gobierno Corporativo de la Empresa. Barcelona: Bosh, 2015.

TRUBEK, David M. Law and Development: Then and Now. Proceedings of the Annual Meeting (American Society of International Law), Are International Institutions Doing Their Job? American Society of International Law. v. 90, n. March 27-30, p. 223-226. 1996.

TRUBEK, David M. The "Rule of Law" in Development Assistance: Past, Present, and Future. en Y. MATSUURA. The Role Of Law In Development Past, Present And Future. Nagoya University CALE Books. 2005.

TRUBEK, David M. Law and development: Forty years after 'Scholars in Self-Estrangement'. University of Toronto Law Journal. University of Toronto Press. v. 66, n. 3, Summer, p. 301-329. 2016.

UNITED NATIONS. GENERAL ASSEMBLY. Promotion and protection of all human rights, civil, political, economic, social and cultural rights, including the right to development. Disponible en: https: //undocs.org/A/HRC/32/L.20. Acceso en: 04 de enero 2018. 


\section{COMO FAZER REFERÊNCIA AO ARTIGO (ABNT):}

Fuller, Greice Patricia; Lopez, José Luiz Bátiz. Empresa, derechos humanos y sociedad de la información. Revista Eletrônica do Curso de Direito da UFSM, Santa Maria, RS, v. 14, n. 2, e33710, maio./ago. 2019. ISSN 1981-3694. DOI: http://dx.doi.org/10.5902/1981369433710. Disponível em: https://periodicos.ufsm.br/revistadireito/article/view/33710 Acesso em: dia mês. ano.

Direitos autorais 2019 Revista Eletrônica do Curso de Direito da UFSM

Editores responsáveis: Rafael Santos de Oliveira e Angela Araujo da Silveira Espindola

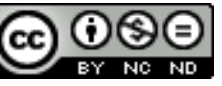

Esta obra está licenciada com uma Licença Creative Commons Atribuição-NãoComercial-SemDerivações 4.0 Internacional.

\section{SOBRE OS AUTORES}

\section{GReice PATRÍcia Fuller}

Pós-Doutora em Direito na Universidad de Navarra /Espanha com bolsa da CAPES (2018). Doutora e Mestre em Direito das Relações Sociais, pela Pontifícia Universidade Católica de São Paulo (PUC/SP). Especialista em Direito Espanhol para Juristas estrangeiros pela Universidad de Alcalá - Madrid (2017). Professora dos Cursos de Graduação das Faculdades de Direito e Economia e Pós-Graduação Lato Sensu de Direitos Difusos e Coletivos da Pontifícia Universidade Católica de São Paulo (PUC/SP). Professora dos Cursos de Graduação da Faculdade de Direito do Centro Universitário das Faculdades Metropolitanas Unidas (FMU). Professora do Programa de Mestrado em Direito da Sociedade da Informação Centro Universitário das FAculdades Metropolitanas Unidas (FMU). Professora da Escola Paulista da Magistratura de São Paulo. (EPM)). Coordenadora do Grupo de Crimes Ambientais da Comissão Permanente do Meio Ambiente OAB/SP. Membro efetiva da Comissão Permanente do Meio Ambiente OAB/SP. Avaliadora externa do Conselho Nacional de Pesquisa e Pós-Graduação em Direito (Conpedi), Revista Jurídica da Presidência e da Revista Quaestio luris (ISSN 1516-0351). Membro da Equipe Editorial da Revista de Direito Público (ISSN:2236-1766 - Qualis A1).

\section{JosÉ LUIS BÁTIZ LóPEZ}

Possui mestrado em Estudios del Desarrollo Global pela Universidad Autónoma de Baja California (2006). Atualmente é UCLA Senior Research Associate da University of California, Los Angeles. Tem experiência na área de Direito, com ênfase em Direito Público. 